\title{
Modeling, Simulation and Dynamics Analysis Issues of Electric Motor, for Mechatronics Applications, Using Different Approaches and Verification by MATLAB/Simulink (I).
}

\author{
Ahmad A. Mahfouz \\ Department of Automatic and Mechatronics Systems, Vladimir State University, Vladimir, RF; \\ Alpha Center for Engineering Studies and Technology Researches, Amman, Jordan \\ Email:ahmad_atallah@yahoo.com
}

Mohammed M. K.

Design and production program, Department of Mechanical Engineering, Faculty of Engineering, Taif University, 888, Taif, Saudi Arabia

Email: m.mohamed2000@yahoo.com

Farhan A. Salem

Mechatronics Section. Department of Mechanical Engineering, Faculty of Engineering, Taif University, 888, Taif, Saudi Arabia;

Alpha Center for Engineering Studies and Technology Researches, Amman, Jordan

Email:salem_farh@yahoo.com

\begin{abstract}
The accurate control of motion is a fundamental concern in mechatronics applications, where placing an object in the exact desired location with the exact possible amount of force and torque at the correct exact time is essential for efficient system operation. An accurate modeling, simulation and dynamics analysis of actuators for mechatronics motion control applications is of big concern. The ultimate goal of this paper addresses different approaches used to derive mathematical models, building corresponding simu lin k models and dynamic analysis of the basic open loop electric DC motor system, used in mechatronics motion control applications, particularly, to design, construct and control of a mechatronics robot arm with single degree of freedom, and verification by MATLAB/Simulink. To simplify and accelerate the process of DC motors sizing, selection, dynamic analysis and evaluation for different motion applications, different mathematical models in terms of output position, speed, current, acceleration and torque, as well as corresponding simulink models, supporting MATLAB m.file and general function block models are to be introduced. The introduced models were verified using MATLAB/ Simulink. These models are intended for research purposes as well as for the application in educational process.
\end{abstract}

This paper is part I of writers' research about mechatronics motion control, the ultimate goal of this research addresses design, modeling, simulation, dynamics analysis and controller selection and design issues, of mechatronics single joint robot arm. where a electric DC motor is used and a control system is selected and designed to move a Robot arm to a desired output position, $\theta$ corresponding to applied input voltage, $V_{i n}$ and satisfying all required design specifications.

Index Terms - Electric Motor, PMDC Motor, Separately Excited Motor, Mathematical Model, State Space, Simulation, Response, MATLAB m.file and Function Block

\section{Introduction}

Mechatronic systems often use electric motors to drive their work loads, where electric motors are used to provide rotary or linear motion to a variety of electromechanical devices and servo systems [1]. Depending on application (e.g. robots, electric vehicles, low-to-medium power machine-tools etc.) and desired dynamic and steady state performances, as well as for motor's performance analysis, controller selection and design, it is of concern to derive mathematical models of electric DC motor, and built corresponding Simulink models, that can simplify and accelerate the process of modeling, simulation and dynamic analysis of DC motor motion control for mechatronics applications. 
Motion control systems takes input voltage as actuator input, and outputs linear or rotational position/speed/ acceleration/ torque, the most used actuator for motion control systems is DC motors. A single joint robot arm is an application example of an electro mechanical system used in industrial automation. Each degree of freedom (DOF) is a joint on Robot arm, where arm can rotate or translate, each DOF requires an actuator. When designing and building a robot arm it is required to have as few degrees of freedom allowed for given application, a single jo int Robot arm is a system with one DOF. In industrial automation, the control of motion is a fundamental concern, putting an object in the correct place with the right amount of force and torque at the right time is essential for efficient manufacturing operation [2]. To simplify and accelerate the process of DC motors sizing and selection for different applications, We are to model, simulation and analyze the basic open loop DC motor system using different methods and verification by MATLAB/ Simulink, also to suggest MATLAB m.file and function block model for purposes of design and analysis.

\section{Robot Arm System Characteristic}

Single joint robot arm system consists of three parts (Fig. 1); arm, connected to actuator through gear train with gear ratio, $n$.

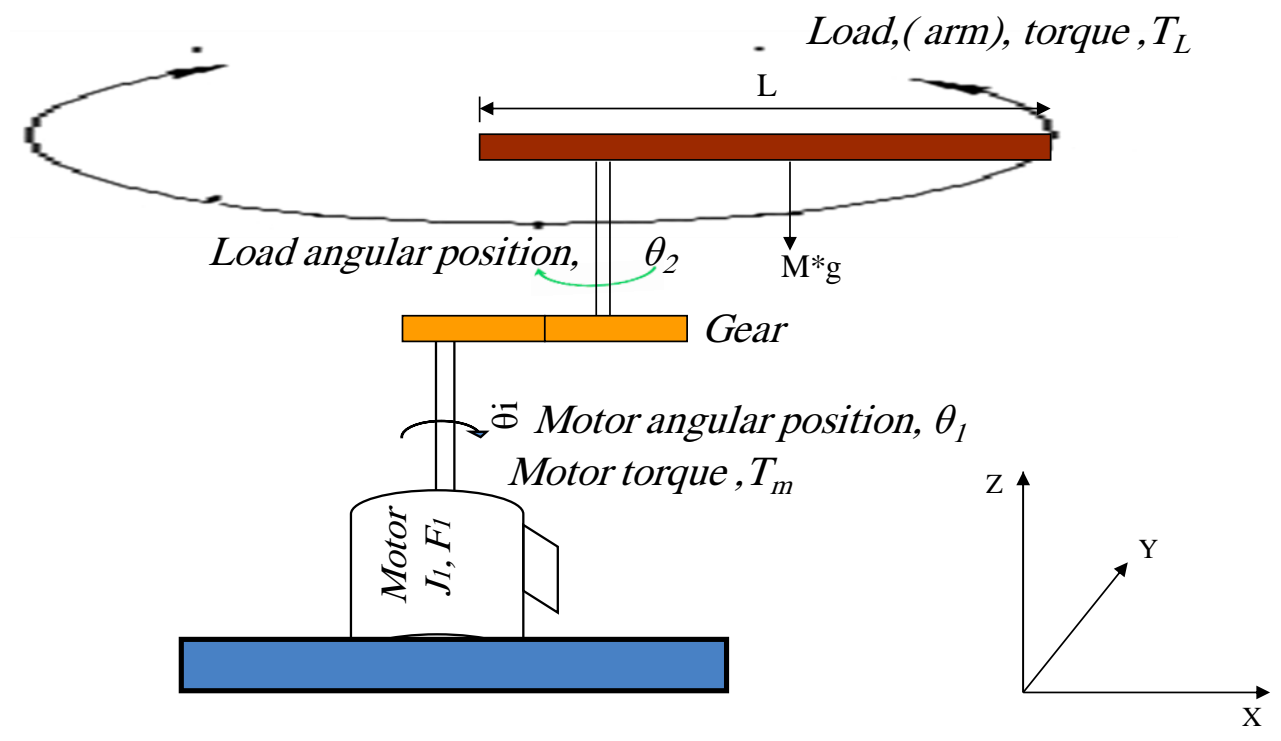

Fig. 1: Schematic model of a single joint (one DOF) robot arm driven by an armature-controlled DC motor

The actuator used is a DC motor shown in Fig.2. DC motor turns electrical energy into mechanical energy and produces the torque required to move the load to the desired output position, $\theta_{L}$, or rotate with the desired output angular speed, $\omega_{L}$. The produced torque is exerted to accelerate the rotor and ultimately this mechanical power will be transmitted through a gear set to robot arm, therefore, part of the torque produced will cause a rotational acceleration of the rotor, depending on its inertia, $J_{m}$, and the other part of the energy will be dissipated in the bearings according to its viscous friction, $b_{m}$ and the rotational speed.

\section{Modeling the Electric Motor}

DC motors (machines) consist of one set of a current carrying conductive coil, called an armature, inside another set of a current carrying conductive coils or a set of permanent magnets, called the stator. The input voltage can be applied to armature terminal (armature current controlled DC motor), or to carrying conductive coils terminals (field current controlled DC motor). This current will generate lines of flux around the armature and affect the lines of flux in the air gap between two coils, generating two magnetic fields, the interaction between these two magnetic fields (attract and repel one another) within the DC motor, results in a torque which tends to rotate the rotor (the rotor is the rotating member of the motor). As the rotor turns, the current in the windings is commutated to produce a continuous torque output resulting in motion.

DC machines are characterized by their versatility. By means of various combinations of shunt-, series-, and separately-excited field windings, they can be designed to display a wide variety of volt-ampere or speed-torque characteristics for both dynamic and steady-state operation. Because of the ease with which they can be controlled, systems of DC machines have been frequently used in many applications requiring a wide range of motor speeds and a precise output motor control [3, 4]. The selection of motor for a specific application is dependent on many factors, such as the intention of the application, correspondingly allowable variation in speed and torque and ease of control, etc. 
The dynamic equations of DC motors can be derived, mainly based on the Newton's law combined with the Kirchoff's laws. The fundamental system of electromagnetic equations for any electric motor is given by $[5,6]$ :

$$
\left.\begin{array}{l}
u_{s}=R_{s} i_{s}+\frac{d \psi_{s}}{d t}+j \omega^{k} \psi_{s} \\
u_{s}=R_{R} i_{R}+\frac{d \psi_{R}}{d t}+j\left(\omega^{k}-P_{b} \omega_{m}\right) \psi_{R} \\
\psi_{s}=L_{s} i_{s}+L_{\mu} i_{R} \\
\psi_{R}=L_{R} i_{R}+L_{\mu} i_{S}
\end{array}\right\}
$$

where : $\omega^{k}$ the angular speed of rotating coordinate system (reference frame), Depending on motor construction (AC or DC), the method of the supply and the coordinate system (stationary or rotating with the rotor or stator flux) the above mentioned model becomes transformed to the desirable form [7], A designer can often make a linear approximation to a nonlinear system. Linear approximations simplify the analysis and design of a system and are used as long as the results yield a good approximation to reality [8].In modeling DC motors and in order to obtain a linear model, the hysteresis and the voltage drop across the motor brushes is neglected, and the motor input voltage may be applied to the field or armature terminals. In this paper we are most concerned with armature controlled and field controlled DC motor.

\subsection{Modeling of the Armature Controlled PMDC Motor}

The Permanent Magnet DC (PMDC) motor is an example of electromechanical systems with electrical and mechanical components, a simplified equivalent representation the armature controlled DC motor's two components are shown in Fig.2(a).

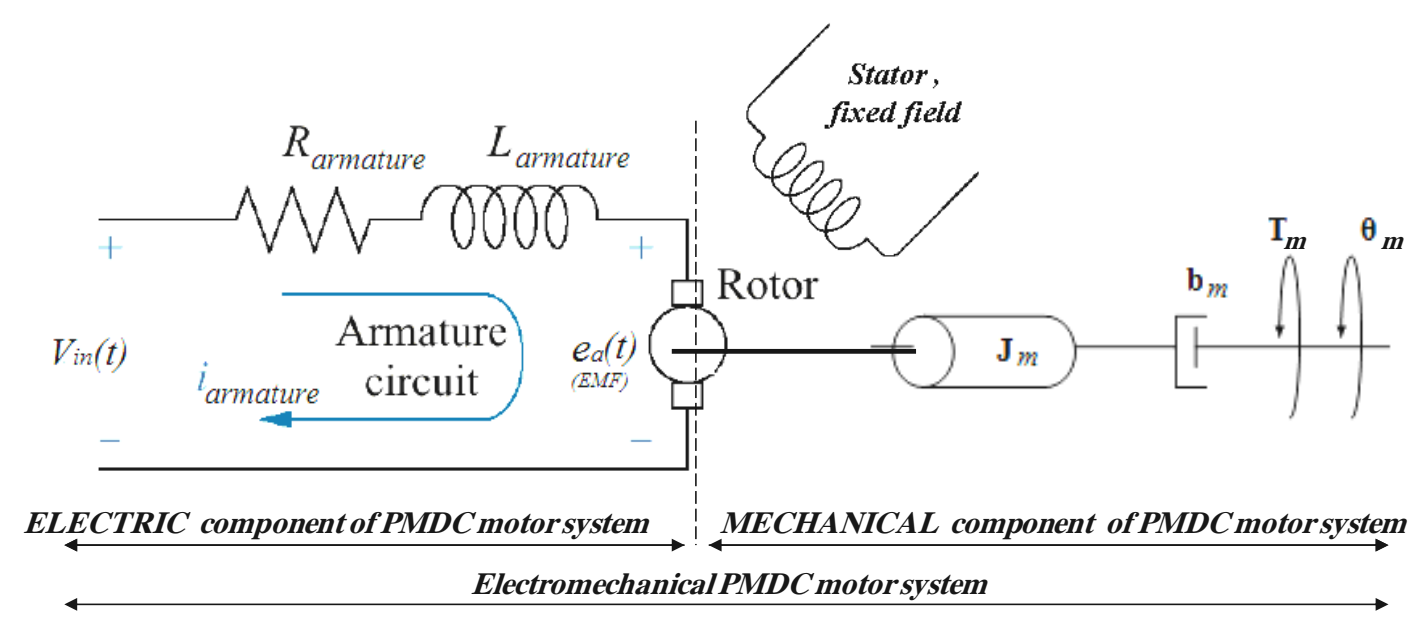

Fig. 2(a): Schematic of a simplified equivalent representation of the armature controlled DC motor's electromechanical components, (PMDC motor)

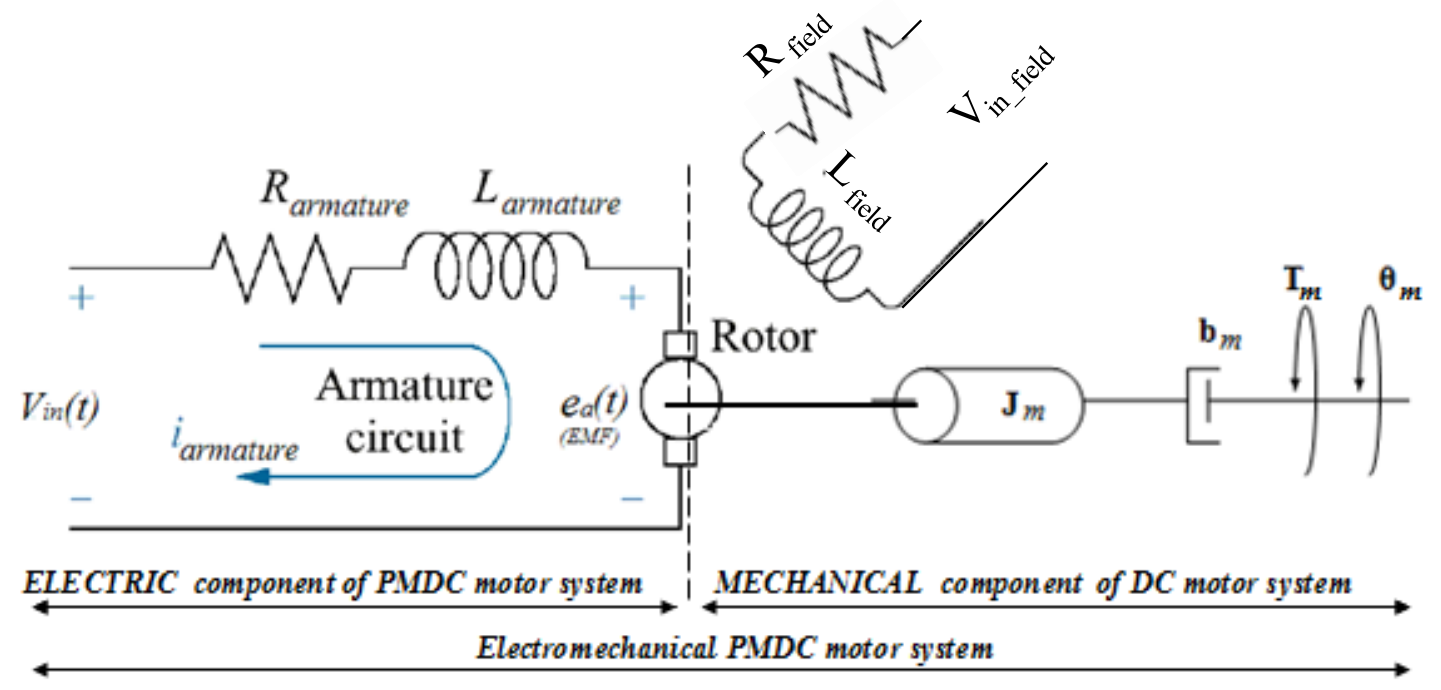

Fig. 2(b): Schematic of a simplified equivalent representation of the field controlled DC motor's electromechanical components 


\subsection{Modeling of Motor Dynamics, Approach I; The Basic Ideal, Linear, PMDC Motor Model}

\subsubsection{Electrical Characteristics of PMDC Motor}

Applying a voltage to motor coils produce a torque in the armature, the torque developed by the motor,$T_{m}$ is related to the armature current, $i_{a}$ by a torque constant, $K_{t}$ and given by the following equation:

$$
\text { Motor Torque }=T_{m}=K_{t} * i_{\mathrm{a}}
$$

The back electromotive force, EMF voltage, $\mathrm{e}_{\mathrm{a}}$ is induced by the rotation of the armature windings in the fixed magnetic field, the polarity of EMF voltage acts in opposition to the current that produces the motion. The EMF is related to the motor shaft angular speed,$\omega_{m}$ by a linear relation given by:

$$
e_{a}(t)=K_{b} \frac{d \theta_{m}(t)}{d t}=K_{b} \omega_{m}
$$

Where: $\mathrm{K}_{\mathrm{b}}$ : EMF constant. Based on the Newton's law combined with the Kirchoff's law, the mathematical model in the form of differential equations describing electric characteristics of the armature controlled PMDC motor can be derived, where the electrical equivalent of the armature circuit, can be described as an inductance, $\mathrm{L}$ in series with a resistance, $\mathrm{R}$ in series with an induced EMF voltage which opposes the voltage source. Applying Kirchoff's law around the electrical loop by summing voltages throughout the R-L circuit gives:

$$
\sum V=V_{i n}-V_{R}-V_{L}-E M F=0
$$

Applying Ohm's law, substituting and rearranging, we get differential equation that describes the electrical characteristics of PMDC motor:

$$
\begin{aligned}
& V_{\text {in }}=R_{a} * i_{a}(t)+L_{a}\left(\frac{d i_{a}(t)}{d t}\right)+K_{b} \frac{d \theta(t)}{d t} \\
& V_{\text {in }}=R_{a} * i_{a}+L_{a}\left(\frac{d i_{a}}{d t}\right)+K_{b} \frac{d \theta}{d t}
\end{aligned}
$$

Taking Laplace transform and rearranging, gives:

$$
\begin{aligned}
& V_{i n}(s)=R_{a} I(s)+L_{a} s I(s)+K_{b} s \theta(s) \\
& \left(L_{a} s+R_{a}\right) I(s)=V_{i n}(s)-K_{b} s \theta(s)
\end{aligned}
$$

\subsubsection{Mechanical characteristics of PMDC motor.}

The torque, developed by motor, produces an angular velocity, $\omega_{m}=d \theta_{m} / d t$, according to the inertia $J$ and damping friction, $b$, of the motor and load. Performing the energy balance on the PMDC motor system the mathematical model in the form of differential equations describing mechanical characteristics can be derived; the sum of the torques must equal zero, we have:

$$
\begin{gathered}
\sum T=J * \alpha=J * d^{2} \theta / d t^{2} \\
T_{e}-T_{\alpha}-T_{\omega}-T_{E M F}=0
\end{gathered}
$$

Substituting the following values: $\mathrm{T}_{\mathrm{e}}=K_{t} * i_{a}, T_{\alpha}=$ $J_{m} * d^{2} \theta / d t^{2}$, and $T_{\omega}=b_{m} * d \theta / d t$, in open loop PMDC motor system without load attached, that is the change in $T_{\text {motor }}$ is zero, gives:

$$
K_{t} * i-T_{\text {Load }}-J_{m}\left(\frac{d^{2} \theta}{d t^{2}}\right)-b_{m}\left(\frac{d \theta}{d t}\right)=0
$$

Taking Laplace transform and rearranging, gives:

$$
\begin{gathered}
K_{t} * I(s)-J_{m} *^{2} \theta(s)-b_{m} *_{s} \theta(s)=0 \\
K_{t} I(s)=\left(J_{m} s+b_{m}\right) s \theta(s)
\end{gathered}
$$

The electrical and mechanical PMDC motor two components are coupled to each other through an algebraic torque equation given by (1). In summary; a satisfactory PMDC motor equations that describes the electric and mechanical characteristics of a practical PMDC motor for many purposes is given by Eqs. (1), (2),(5) and (7).

\subsection{Deriving PMDC Motor Open Loop System Transfer Functions}

To derive the PMDC motor transfer function, we need to rearrange (6) describing electrical characteristics of PMDC, such that we have only $I(s)$ on the right side, then substitute this value of $I(s)$ in (7) describing PMDC mechanical characteristics, as follows:

$$
I_{a}(s)=\left[\frac{1}{\left(L_{a} s+R_{a}\right)}\right]\left[V_{i n}(s)-K_{b} \omega(s)\right]
$$

The PMDC motor electric component transfer function relating armature current, and voltage, is given by:

$$
\frac{I_{a}(s)}{\left[V_{i n}(s)-K_{b} \omega(s)\right]}=\left[\frac{1}{\left(L_{a} s+R_{a}\right)}\right]
$$

The PMDC motor Mechanical component transfer function in term of output torque and input rotor speed is given by:

$$
\frac{\omega(s)}{\left[K_{t} I_{a}(s)-T_{L}(s)\right]}=\left[\frac{1}{\left(J_{m} s+b_{m}\right)}\right]
$$


In case, no load attached, $T_{\text {load }}=0$, we have:

$$
\frac{\omega(s)}{\left[K_{t} I_{a}(s)\right]}=\left[\frac{1}{\left(J_{m} s+b_{m}\right)}\right]
$$

Now, Substituting (8) in (7), gives:

$$
\begin{aligned}
K_{t}\left[\frac{1}{\left(L_{a} s+R_{a}\right)}\right] & {\left[V_{i n}(s)-K_{b} \omega(s)\right] } \\
& =J_{m} s^{2} \theta(s)+b_{m} s \theta(s)
\end{aligned}
$$

Rearranging (11), and knowing that the electrical and mechanical PMDC motor components are coupled to each other through an algebraic torque equation given by Eq. (1), we obtain the PMDC motor open loop transfer function without any load attached relating the input voltage, $V_{i n}(s)$, to the motor shaft output angle, $\theta_{m}(s)$, given by:

$$
\begin{aligned}
G_{\text {angle }}(s) & =\frac{\theta(s)}{V_{\text {in }}(s)} \\
& =\frac{K_{t}}{\left\{s\left[\left(L_{a} s+R_{a}\right)\left(J_{m} s+b_{m}\right)+K_{t} K_{B}\right]\right\}} \\
G_{\text {angle }}(s) & =\frac{\theta(s)}{V_{\text {in }}(s)} \\
= & \frac{K_{t}}{\left\{\left[L_{a} J_{m} s^{3}+\left(R_{a} J_{m}+b_{m} L_{a}\right) s^{2}+\left(R_{a} b_{m}+K_{t} K_{b}\right) s\right]\right\}}
\end{aligned}
$$

The PMDC motor open loop transfer function relating the input voltage, $V_{i n}(s)$, to the motor shaft output angular velocity, $\omega_{m}(s)$, given by:

$$
\begin{aligned}
G_{\text {speed }}(s) & =\frac{\omega(s)}{V_{\text {in }}(s)} \\
& =\frac{K_{t}}{\left\{\left[\left(L_{a} s+R_{a}\right)\left(J_{m} s+b_{m}\right)+K_{t} K_{b}\right]\right\}} \\
G_{\text {speed }}(s) & =\frac{\omega(s)}{V_{\text {in }}(s)} \\
= & \frac{K_{t}}{\left\{\left[L_{a} J_{m} s^{2}+\left(R_{a} J_{m}+b_{m} L_{a}\right) s+\left(R_{a} b_{m}+K_{t} K_{b}\right)\right]\right\}}
\end{aligned}
$$

Here note that the transfer function $G_{\text {angle }}(s)$ can be expressed as: $G_{\text {angle }}(s)=G_{\text {speed }}(s) *(1 / s)$. This can be obtained using MATLAB, by the following, code:

$$
>G_{-} \text {angle }=t f(1,[1,0]) * G \_ \text {speed }
$$

Where: running $\mathrm{tf}(1,[1,0])$, will return $1 / \mathrm{s}$
The open loop PMDC motor transfer function relating the torque developed by the motor, $T_{m}(s)$ and the output motor shaft angle $\theta_{m}(s)$, is obtained by rearranging Eq.(6), to give:

$$
\frac{\theta_{m}(s)}{T_{m}(s)}=\frac{1}{\left(J_{m} s^{2}+b_{m} s\right)}
$$

The open loop PMDC motor transfer function relating the armature voltage, $V_{i n}(s)$, to the armature current, $I_{a}(s)$, directly follows:

$$
\frac{I_{a}(s)}{V_{i n}(s)}=\frac{\frac{1}{L_{a}}\left(s+\frac{L_{a}}{J_{m}}\right)}{s^{2}+\left(\frac{R_{a}}{L_{a}}+\frac{b_{m}}{J_{m}}\right) s+\left(\frac{R_{a} b_{m}}{L_{a} J_{m}}+\frac{K_{b} K_{t}}{L_{a} J_{M}}\right)}
$$

\subsection{Modeling of Motor dynamics, approach II :}

The armature, $i_{a}$ current can be found by rearranging the torque equation given by (1), rearranging and taking Laplace transform, gives:

$$
I_{a}(s)=\frac{T_{m}(s)}{K_{t}}
$$

To find the transfer function of the PMDC motor, in terms of input voltage $V_{\text {in }}$ and output angular position $\theta_{m}$, we first substitute (3), and (16), in (5) and taking Laplace transform, this gives:

$$
V_{i n}(s)=\frac{\left(L_{a} s+R_{a}\right) T_{m}(s)}{K_{t}}+K_{b} s \theta(s)
$$

The torque developed by the motor, $T_{m}(s)$, in terms of output angle $\theta_{m}(s)$, is given by (14), substituting in (17), and manipulating, gives:

$$
V_{\text {in }}(s)=\frac{\left(L_{a} s+R_{a}\right)\left(J_{m} s^{2}+b_{m} s\right) \theta(s)}{K_{t}}+K_{b} s \theta(s)
$$

Manipulating and Rearranging gives:

$$
\begin{gathered}
V_{i n}(s)=\left[\frac{\left(R_{a}\right)\left(J_{m} s^{2}+b_{m} s\right)}{K_{t}}+K_{b} s\right] \theta(s) \\
V_{\text {in }}(s)=\frac{\left[\left(L_{a} s+R_{a}\right)\left(J_{m} s^{2}+b_{m} s\right)+K_{t} K_{b} s\right] \theta(s)}{K_{t}}
\end{gathered}
$$




$$
\begin{aligned}
G_{\text {angle }}(s) & =\frac{\theta(s)}{V_{\text {in }}(s)} \\
& =\frac{K_{t}}{\left\{\left[L_{a} J_{m} s^{3}+\left(R_{a} J_{m}+b_{m} L_{a}\right) s^{2}+\left(R_{a} b_{m}+K_{t} K_{b}\right) s\right]\right\}}
\end{aligned}
$$

Armature inductance, $L_{a}$ is low compared to the armature resistance, $R_{a}$ (discussed later). Neglecting motor inductance by assuming, $\left(L_{a}=0\right)$, manipulating and gives:

$$
\frac{\theta(s)}{V_{i n}(s)}=\frac{\frac{K_{t}}{R_{a} J_{a}}}{s\left[s+\frac{1}{J_{m}}\left(b_{m}+\frac{K_{t} K_{b}}{R_{a}}\right)\right]}
$$

\subsection{Modeling of Motor Dynamics, Approach III :}

The torque is given by:

$$
T=j d^{2} \theta / d t^{2}=J d \omega / d t
$$

Also torque is given by (2), equating these two equations, separating armature current $i_{a}$, taking Laplace transform, gives:

$$
\begin{aligned}
& K_{t} * i_{a}=J_{m} d^{2} \theta / d t^{2} \\
& \mathrm{I}_{\mathrm{a}}(\mathrm{s})=\frac{\mathrm{J}_{\mathrm{m}} \mathrm{s}^{2} \theta(s)}{K_{t}}
\end{aligned}
$$

Substituting (19) in (6), and rearranging gives:

$$
\begin{aligned}
& \left(L_{a} s+R_{a}\right) \frac{\mathrm{J}_{\mathrm{m}} \mathrm{s}^{2} \theta(s)}{K_{t}}=V_{\text {in }}(s)-K_{b} s \theta(s) \\
& \left(L_{a} s \frac{\mathrm{J}_{\mathrm{m}} \mathrm{s}^{2} \theta(s)}{K_{t}}+R_{a} \frac{\mathrm{J}_{\mathrm{m}} \mathrm{s}^{2} \theta(s)}{K_{t}}\right)+K_{b} s \theta(s)=V_{\text {in }}(s) \\
& G_{\text {angle }}(s)=\frac{\theta(s)}{V_{\text {in }}(s)}=\frac{K_{t}}{\left[L_{a} J_{m} s^{3}+R_{a} J_{m} s^{2}+K_{t} K_{b} s\right]}
\end{aligned}
$$

To write transfer function in terms of output speed $\omega$, we rewrite the torque Eq.(19) in terms of output speed $K_{t} * i_{a}=J_{m} d \omega / d t$, and repeat previous steps.

\subsection{Simplification of Open Loop PMDC Motor System Transfer Functions Models}

Based on the fact that, the PMDC motor response is dominated by the slow mechanical time constant, where the electric time constant is much faster (e.g. ten times) than the mechanical time constant, this can motivate us to assume that the armature inductance, $L_{a}$ is low compared to the armature resistance, $R_{a}$. neglecting motor inductance, $\left(L_{a}=0\right)$, will result in the following simplified first order form of PMDC motor transfer function in terms input voltage, $V_{i n}(\mathrm{~s})$ and output speed ,$\omega_{m}(\mathrm{~s})$ given by:

$$
\begin{aligned}
G_{\text {speed }}(s) & =\frac{\omega(s)}{V_{\text {in }}(s)} \\
& =\frac{K_{t}}{\left\{\left[\left(R_{a} J_{m}\right) s+\left(R_{a} b_{m}\right)+K_{t} K_{b}\right]\right\}}
\end{aligned}
$$

Rearranging this first order equation into standard first order transfer function form, yields:

$$
\begin{aligned}
G_{\text {speed }}(s) & =\frac{\omega(s)}{V_{\text {in }}(s)} \\
& =\frac{\frac{K_{b} K_{t}}{\left(R_{a} b+K_{t} K_{b}\right)}}{\left(\frac{R_{a} J}{\left(R_{a} b+K_{t} K_{b}\right)}\right) s+1}=\frac{K_{B}}{\tau s+1}
\end{aligned}
$$

A simplified first order form of PMDC motor transfer function in terms of output angle, can is also be obtained by substituting $\left(L_{a}=0\right)$, and given by:

$$
\begin{aligned}
G_{\text {angle }}(s) & =\frac{\theta(s)}{V_{\text {in }}(s)} \\
& =\frac{\frac{K_{t}}{R_{a} J_{M}}}{s\left[s+\frac{1}{J_{m}}\left(b_{m}+\frac{K_{t} K_{b}}{R_{a}}\right)\right]}
\end{aligned}
$$

Eq.(12) can be simplified by substituting, $\left(L_{a}=0\right)$, to have any of the following two forms, where the second form given by (22) can be simplified to second order system, given by:

$$
\begin{aligned}
G_{\text {angle }}(s) & =\frac{\theta(s)}{V_{\text {in }}(s)} \\
& =\frac{K_{t}}{\left[R_{a} J_{m} s^{2}+\left(R_{a} b_{m}+K_{t} K_{b}\right) s\right]} \\
& =\frac{K}{s(s+a)}
\end{aligned}
$$

Also (20) by substituting, $\left(L_{a}=0\right)$, can be simplified to second order systemrelating input voltage and output angle, as well as equation relating input voltage and output speed, to be given by: 


$$
\begin{aligned}
G_{\text {angle }}(s) & =\frac{\theta(s)}{V_{\text {in }}(s)} \\
& =\frac{K_{t}}{s\left(R_{a} J_{m} s+K_{t} K_{b}\right)} \\
G_{\text {speed }}(s) & =\frac{\omega(s)}{V_{\text {in }}(s)} \\
& =\frac{K_{t}}{\left(R_{a} J_{m} s+K_{t} K_{b}\right)}
\end{aligned}
$$

\subsection{Nonlinear Model of PMDC Motor}

Mechanical control systems are supposed to operate with high accuracy and speed despite adverse effects of system nonlinearities and uncertainties. This robustness property is of great importance if the system is part of a robotic or servo system, which requires insensitivity to unmodeled dynamics [11,12]. The ideal simplified PMDC motor model rarely accurate compared with actual results and measurements, since note all factors are considered. To obtain the full system model, major mechanical and electrical nonlinearities such as saturation, coulomb friction and backlash must be included in the model. Here we will derive more an actual equations of PMDC motor, identifying all possible parameters, (actual simulink model is shown in Fig.7). Coulomb friction is a non-linear element in which forces tend to appose the motion of bodies in contact in mechanical systems, it acts as disturbance torque feedback for the mechanical system, Coulomb friction is considered to be a constant retarding force but is discontinuous over zero crossings, that is, when a DC motor reverses direction it must come to a stop at which point Coulomb friction drops to zero and then opposes the reversed direction. In effect Coulomb friction is constant when rotational velocity is not zero [3]. Introducing in Eq.(6) ,Coulomb friction and dead zone friction, where $\left(T_{\text {load }}=0\right)$, we have:

$$
\begin{gathered}
K_{t} * i_{a}=T_{\alpha}+T_{\omega}+T_{\text {load }+} T_{f} \\
K_{t} * I(s)-J_{m} *^{2} \theta(s)-b_{m} *_{s} \theta(s) . T_{f}=0
\end{gathered}
$$

At steady state conditions, $d / d t=0$, gives:

$$
\begin{aligned}
& K_{t} * i_{a}=-b * \omega-T_{f} \\
& T_{f}=K_{t} * i_{a}-b * \omega
\end{aligned}
$$

\section{PMDC Motor Model Representation, Simulation and Analysis}

\subsection{PMDC Motor Model Representation Using Block Diagrams}

Applying a voltage, $V_{i n}$, to motor coils produce a torque in the armature. The produced torque produces an angular shaft velocity, $\omega=d \theta / d t$, according to the inertia $J$ and viscous friction $b$, the armature will rotate at a speed and direction dependent on the applied voltage and polarity. Theoretically, as a result of applied voltage the motor shaft should continue to accelerate to a higher and higher speed unless there is a force that works in opposition to the applied voltage, this force is back electromotive force, EMF, $\mathrm{e}_{\mathrm{b}}$, where because the rotation of the PMDC motor's armature windings in the fixed magnetic field generates, EMF, that opposes the applied voltage. Using this we can build the block diagram model of the open loop PMDC motor system. The PMDC motor electric component transfer function relating input armature current, $i_{a}$ and voltage $V_{i n}$, is given by (9), the DC motor mechanical component transfer function relating output torque and input rotor speed is given by (10), also the electrical and mechanical PMDC motor components are coupled to each other through an algebraic torque equation given by (2), using these relations we can build the block diagram model of the open loop PMDC motor system shown in Fig.3, block diagram model shows the feedback action in the open loop PMDC motor system, also shows that the electrical and mechanical PMDC motor components are coupled to each other through torque constant $K_{t}$.

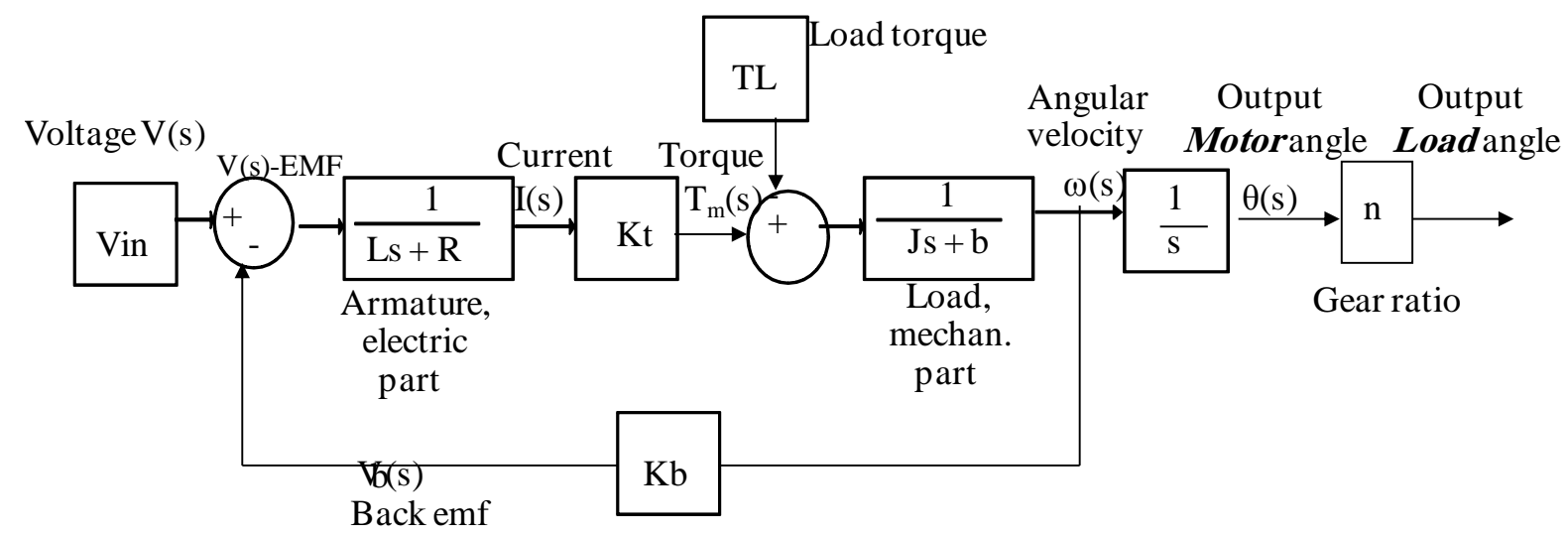

Fig. 3: The block diagram representation of open loop PMDC motor system 


\subsection{The Feedback Action of the Open Loop DC Motor System}

Basically the DC motor is an open-loop system, to maintain a constant armature output angular velocity, (an increasing angle at constant value) the DC motor exhibits a speed feedback, this speed feedback is achieved by motor's built-in velocity feedback factor $K_{b}$, (The back-EMF constant), this closed loop is a accomplished as follows; If the load on the motor increases due to an increase in viscous friction, $b_{m}$ then the steady state angular velocity of the motor will reduce, this can be shown by equation $K_{t} * i_{a}=b_{m} * \omega_{m}$. Rearranging, to obtain angular velocity we have, equation $\omega_{m}=K_{t} * i_{a} / b_{m}$. This equation means an increase in viscous friction, $b_{m}$ will result in reduction in steady state angular velocity of the motor. A reduction in steady state angular velocity produces a reduction in the back EMF, this is can be seen from (3). This change results in an increase in armature current which increases the developed torque, this is can be seen from (2) that closes the loop to maintain a constant armature output angular velocity.

\section{State Space Representation of PMDC Open Loop System}

The state variables (along with the input functions) used in equations describing the dynamics of a system, provide the future state of the system. Mathematically, the state of the system is described by a set of first-order differential equation in terms of state variables. The state space model takes the following form [9]:

$$
\begin{aligned}
& \frac{d x}{d t}=A x+B u \\
& y=C X+D u
\end{aligned}
$$

Rearranging (5) and (6) to have the below two first order equations, relating the angular speed and armature current:

$$
\begin{gathered}
\frac{d \omega}{d t}=\frac{K_{t} * i_{a}}{J_{m}}-\frac{b_{m} * \omega}{J_{m}}-\frac{T_{L}}{J_{m}} \\
\frac{d i_{a}}{d t}=-\frac{R_{a} * i_{a}}{L_{a}}-\frac{K_{b} * \omega}{L_{a}}-\frac{V_{i n}}{L_{a}}
\end{gathered}
$$

Looking at the DC motor output shaft position $\theta$, and choosing the state variable to be the motor shaft output position $\theta_{m}$, velocity $\omega_{m}$ and armature currents $i_{a}$ :

$$
\begin{aligned}
& x_{1}=\theta \\
& x_{2}=\frac{d \theta}{d t} \\
& x_{3}=i_{a}
\end{aligned}
$$

$$
\begin{aligned}
& x_{1}^{\prime}=\frac{d \theta}{d t}=x_{2} \\
& x_{2}^{\prime}=\frac{d^{2} \theta}{d t^{2}}=\frac{d \omega}{d t}=\frac{K_{t} * i_{a}}{J_{m}}-\frac{b_{m} * \omega}{J_{m}}-\frac{T_{L}}{J_{m}} \\
& x_{3}^{\prime}=\frac{d i_{a}}{d t}=-\frac{R_{a} * i_{a}}{L_{a}}-\frac{K_{b} * \omega}{L_{a}}-\frac{V_{i n}}{L_{a}}
\end{aligned}
$$

Substituting state variables, for electric and mechanical part equations rearranging gives:

$$
\begin{gathered}
x_{1}^{\prime}=\frac{d \theta}{d t}=x_{2} \\
x_{2}^{\prime}=-\frac{b_{m}}{J_{m}} x_{2}+\frac{K_{t}}{J_{m}} x_{3}-T_{l} \\
x_{3}^{\prime}=-\frac{K_{b}}{L_{a}} x_{2}-\frac{R_{a}}{L_{a}} x_{3}+\frac{1}{L_{a}} V_{i n} \\
{\left[\begin{array}{l}
\dot{x}_{1} \\
x_{2} \\
x_{3}
\end{array}\right]=\left[\begin{array}{ccc}
0 & 1 & 0 \\
0 & \frac{K_{T}}{J} \\
0 & -\frac{K_{b}}{L_{m}} & -\frac{R_{m}}{L_{m}}
\end{array}\right]\left[\begin{array}{l}
x_{1} \\
x_{2} \\
x_{3}
\end{array}\right]+\left[\begin{array}{c}
0 \\
0 \\
\frac{1}{L_{m}}
\end{array}\right] \mathrm{v}_{\text {in }}{ }^{+}\left[\begin{array}{c}
0 \\
0 \\
-1
\end{array}\right] T_{L}} \\
T_{m}=K_{T} i_{m}=\left[\begin{array}{ll}
0 & 0 \\
K_{T}
\end{array}\right]\left[\begin{array}{c}
x_{1} \\
x_{2} \\
x_{3}
\end{array}\right]
\end{gathered}
$$

Looking at DC motor speed, as being the output, the following state space model obtained:

$$
\begin{aligned}
& \frac{d}{d t}\left[\begin{array}{l}
\dot{\theta} \\
i
\end{array}\right]=\left[\begin{array}{cc}
-\frac{b_{m}}{J} & \frac{K_{t}}{J} \\
-\frac{K_{b}}{L} & -\frac{R}{L}
\end{array}\right]\left[\begin{array}{l}
\dot{\theta} \\
i
\end{array}\right]+\left[\begin{array}{c}
0 \\
\frac{1}{L}
\end{array}\right] V_{\text {in }} \\
& \dot{\theta}=\left[\begin{array}{ll}
1 & 0
\end{array}\right]\left[\begin{array}{c}
\dot{\theta} \\
i
\end{array}\right]+[0] V_{\text {in }}
\end{aligned}
$$

The state space models are the basis for building the simulink model of open loop DC model. 


\section{Simulation and Analysis of PMDC Motor Open Loop System Using Simulink}

Using derived PMDC motor models, the following simulink models for Speed/time, Torque/time, Position/time and Current/time curves can be obtained, these curve can be used to evaluated, test and validate a given DC motor. Running any of the suggested simulink models with particular DC motor's parameters defined, will return curves shown in Fig.9, here notice that, depending on application, different equation was derived; simplified and accurate. The following nominal values for the various parameters of a PMDC motor used: $V_{i n}=12$ Volts; $\quad J_{m}=0.02 \mathrm{~kg} \cdot \mathrm{m}^{2} ; b_{m}=0.03 ; K_{t}$ $=0.023 \mathrm{~N}-\mathrm{m} / \mathrm{A} ; K_{b}=0.023 \mathrm{~V}-\mathrm{s} / \mathrm{rad} ; R_{a}=1 \mathrm{Ohm}$; $L_{a}=0.23$ Henry; $T_{L}=0$ ( no load attached $)$.

6.1 Simulation and analysis of PMDC motor open loop system based in state space representations given by (29) ,is shown in three suggested models in Fig.4(a)(b)(c), running any of these models will return Torque/time, Speed/time, Angle/time and Current/time curves for $12 \mathrm{~V}$ step input shown in Fig.9

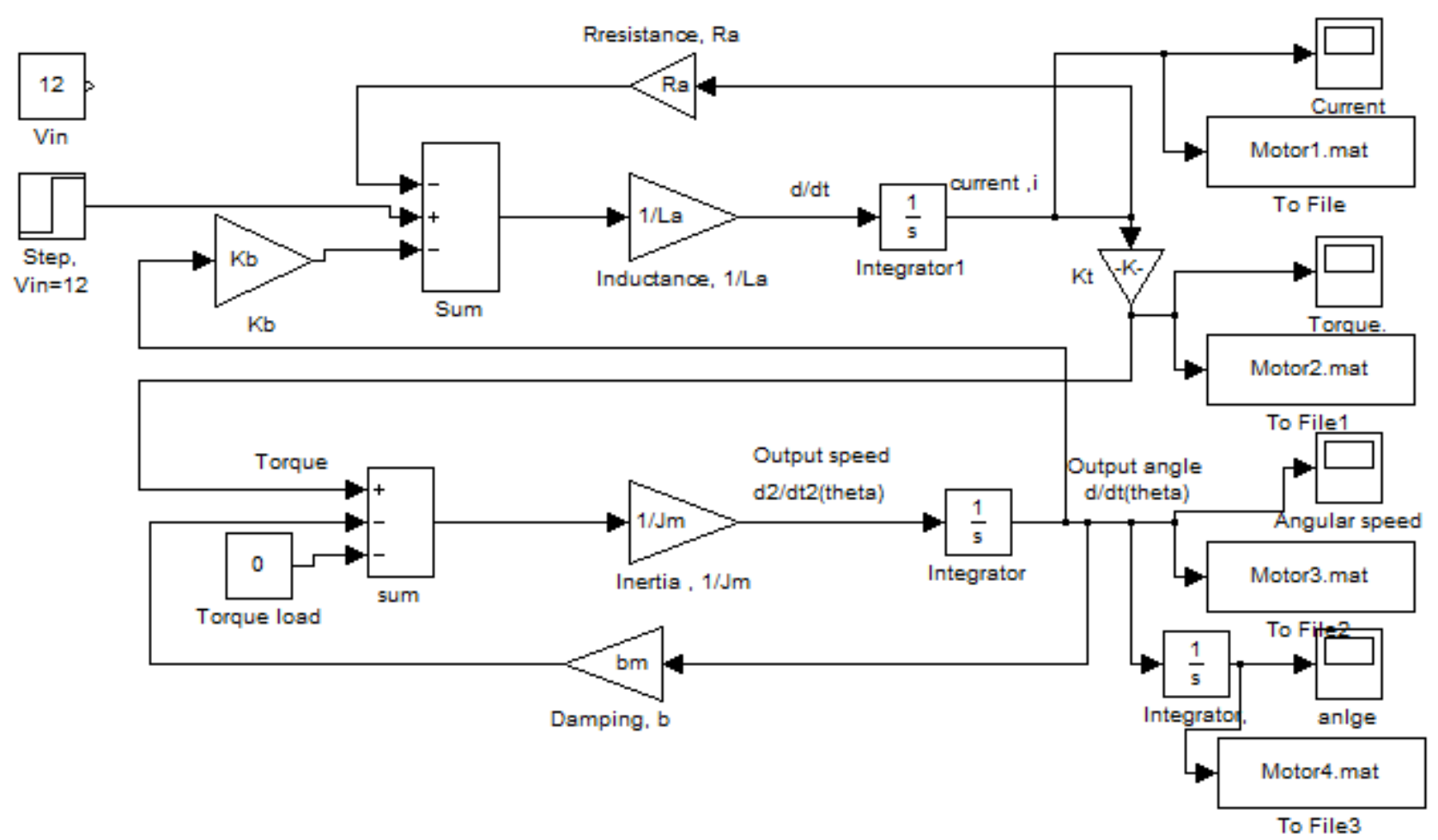

Fig. 4(a): simulink model based on state space representation

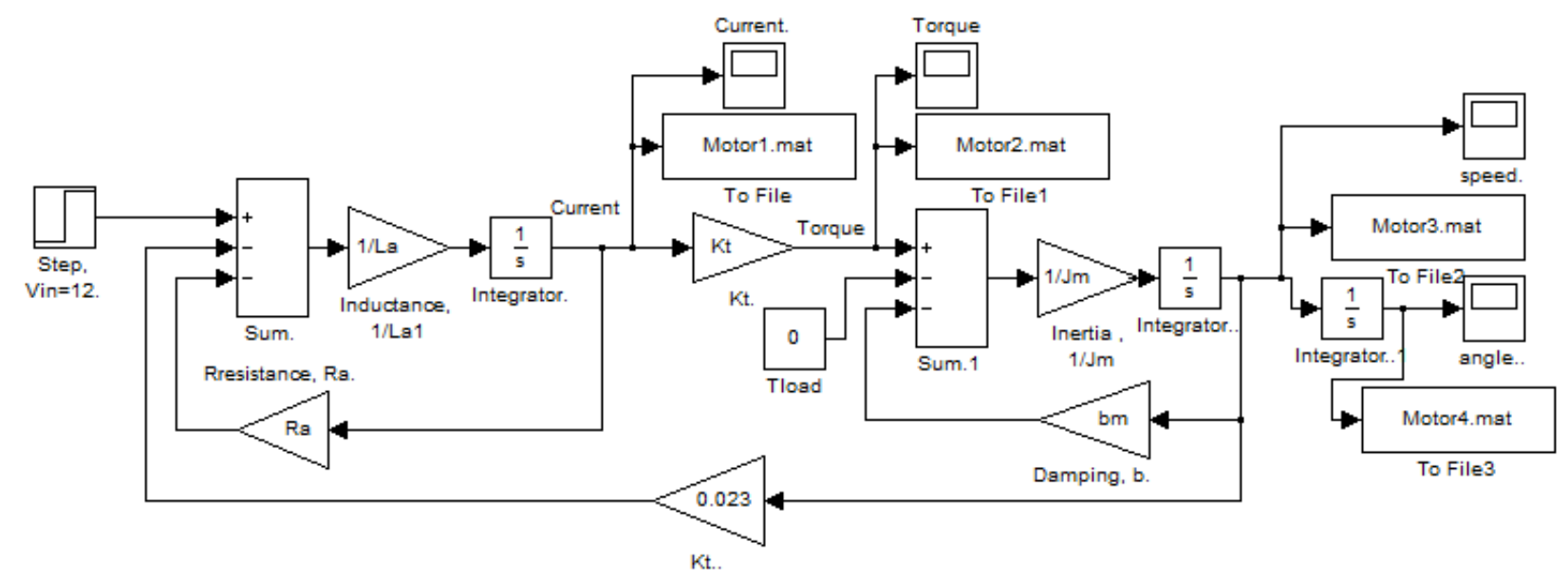

Fig. 4(b): simulink model based on state space representation 


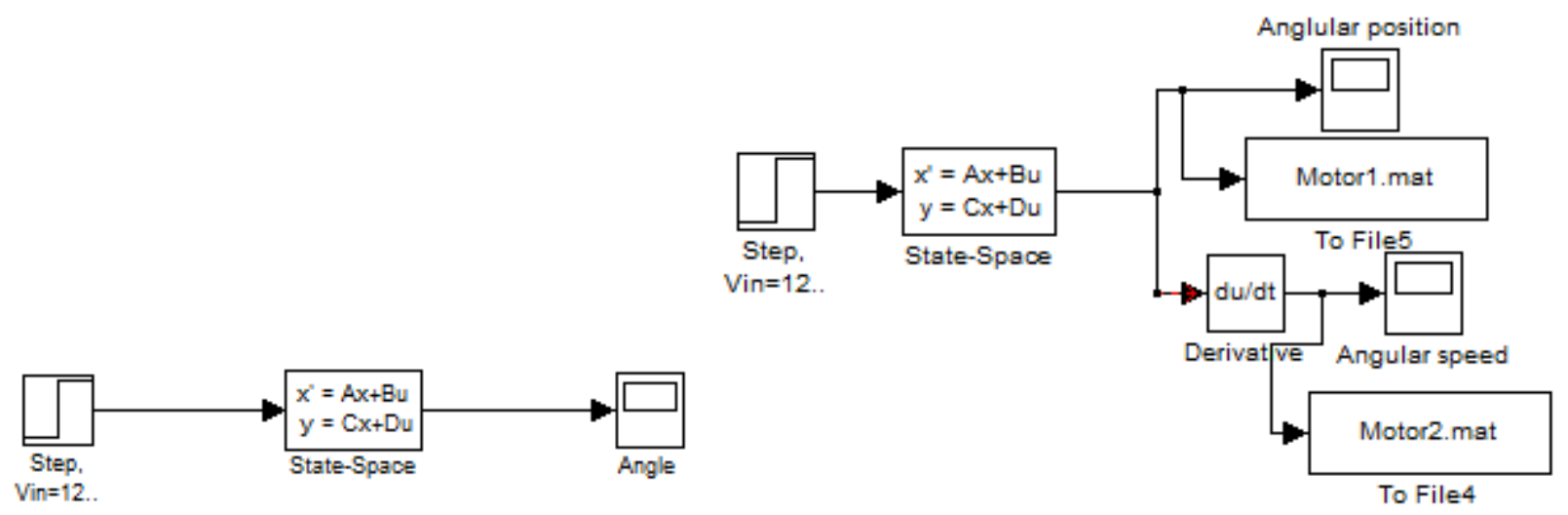

Fig. 4(c): simulink model based on state space representation

6.2 Simulation and analysis of PMDC motor open loop system based on transfer function model given by equations (12) and (13), is shown in Fig.5.

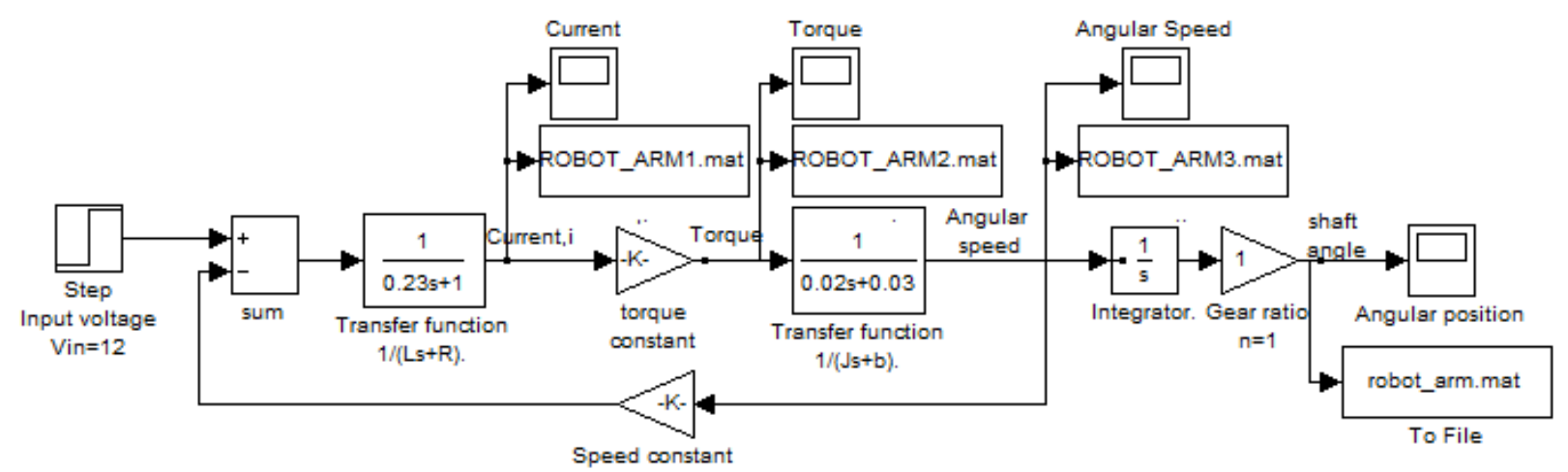

Fig. 5: PMDC motor simulink model based on transfer function model given by (11)

6.3 Block diagram representation of simplified mathematical model in simulink of PMDC motor given by equations (21) and (22), assuming $L_{a}=0$, is shown in Fig. 6.

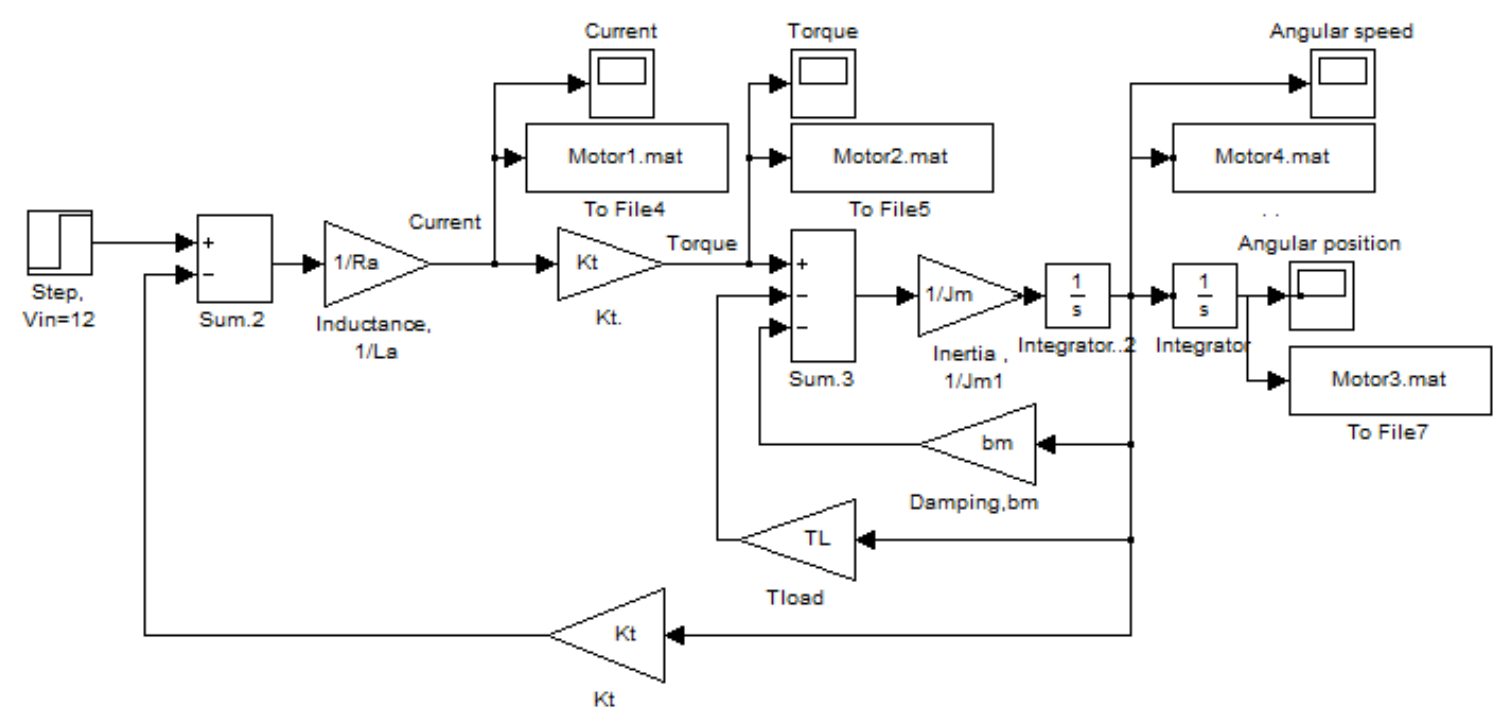

Fig. 6: Simulink model based on simplified mathematical model 


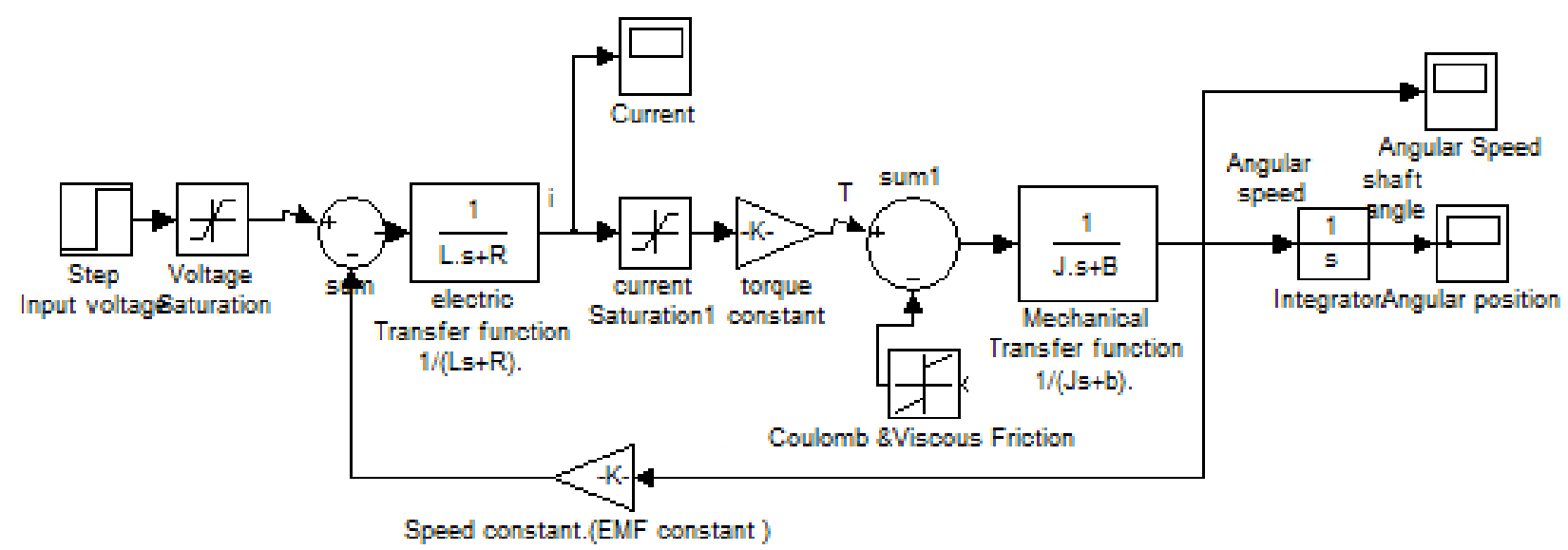

Fig. 7: a suggested full block diagram model of PMDC motor open loop system with introduced saturation and coulomb friction

\subsection{Suggested Function Blocks with Its Function Block Parameters Window}

To simplify and accelerate the process of DC motors sizing and selection for different applications, the following two simplified and accurate a function blocks with its function block parameters windows are introduced below, these models can be used by defining parameters, in corresponding blocks or running m.file with these parameters defined and running the model, will result in corresponding Torque/time, speed/time , position/time and current/time curves for given step input volte.
6.4.1 Simplified function block based on block diagram model, shown in Fig.8(a), is shown in Fig.8(b)(c), running this with nominal values, will return response curves shown in Fig. 9as well as angular acceleration/time curve.

6.4.2 Accurate function block based on simulink model, given in Fig.8(c), is shown in Fig.8(d). Running this with nominal values, will return response curves shown in Fig. 9, as well as angular acceleration/time curve, here note that the current/time curve will differ from that in Fig. 9(a) and is shown in Fig.9(b) , this is because of $(\mathrm{La}=0)$ simplification.

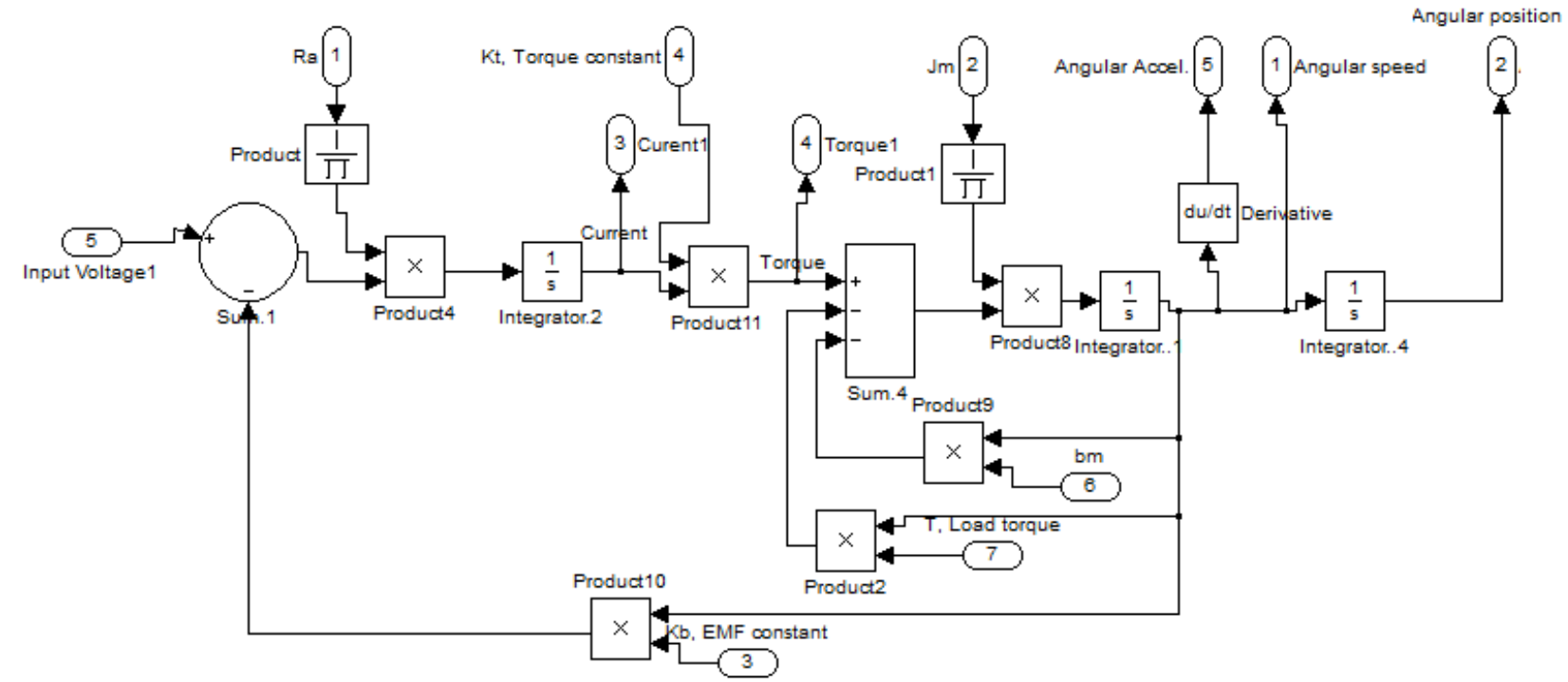

Fig. 8(a): Simplified PMDC motor sub system 


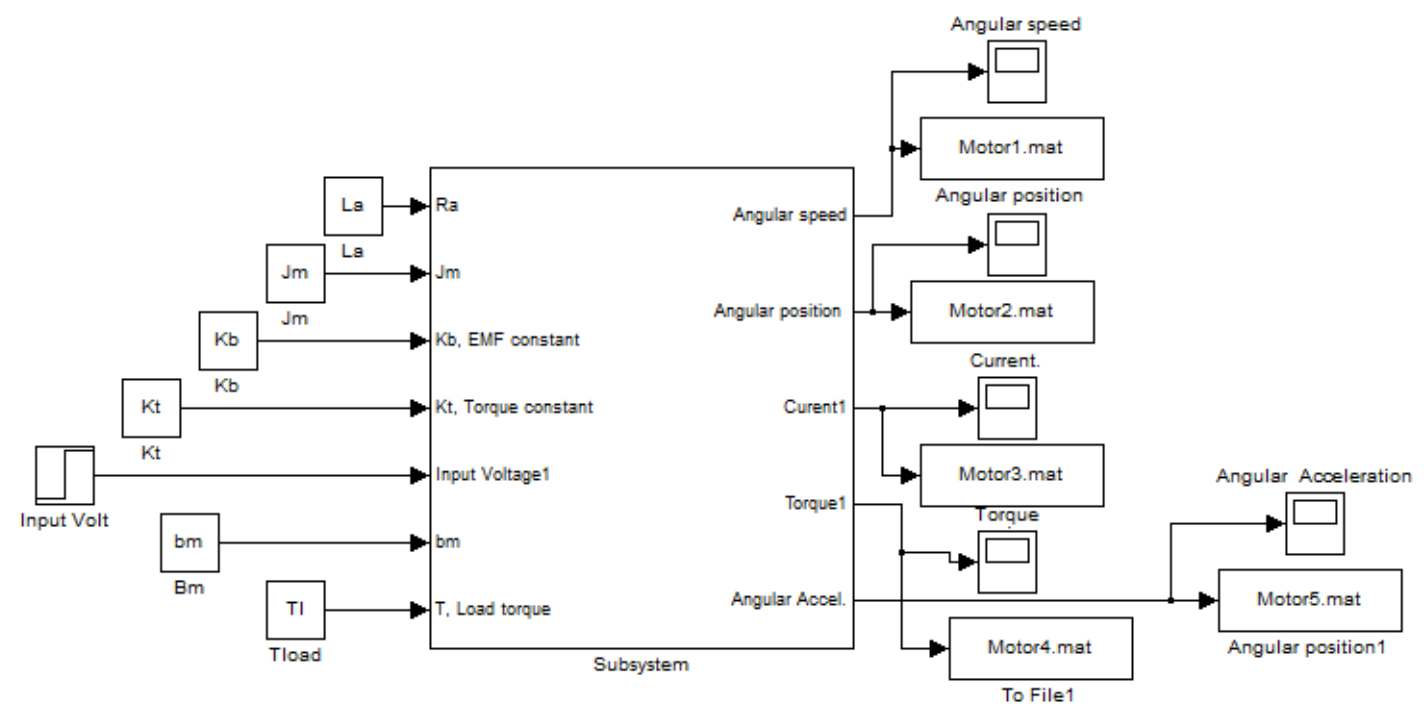

Fig. 8(b): Simplified PMDC function block PMDC motor sub system

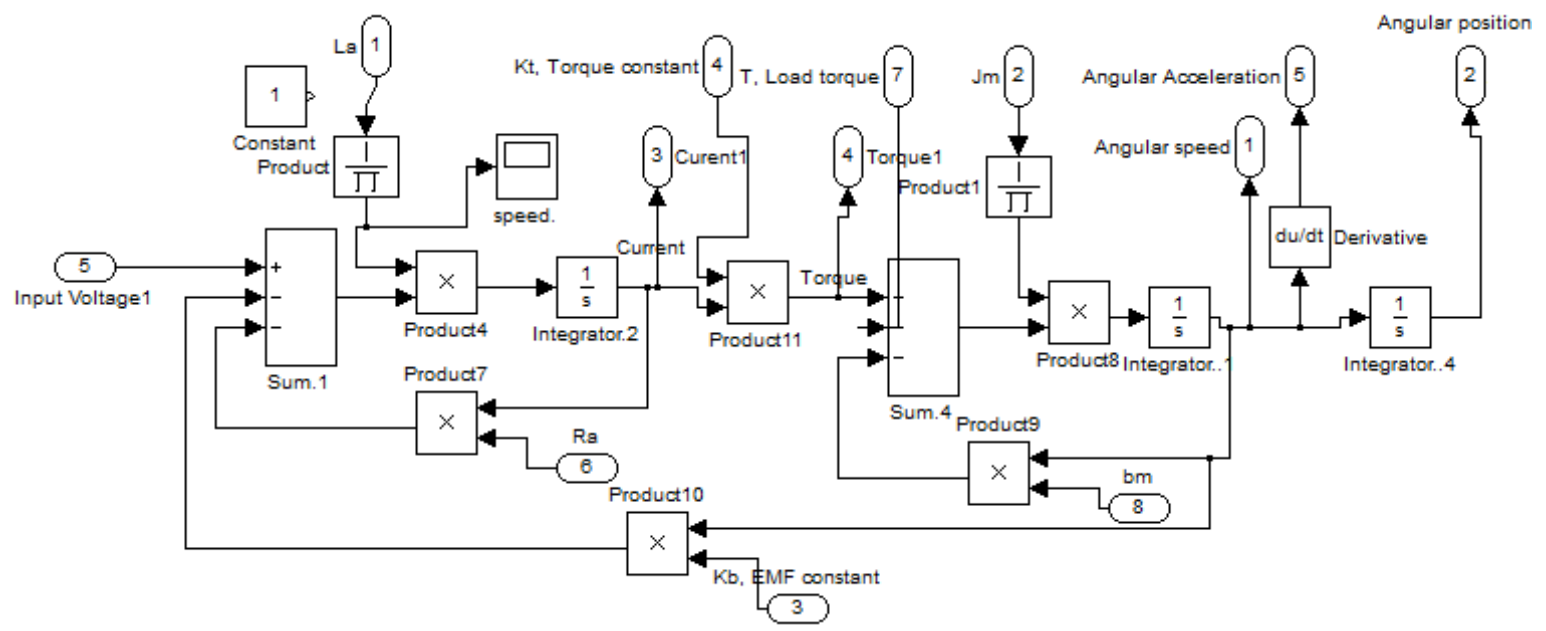

Fig. 8(c): Simplified PMDC motor subsystem

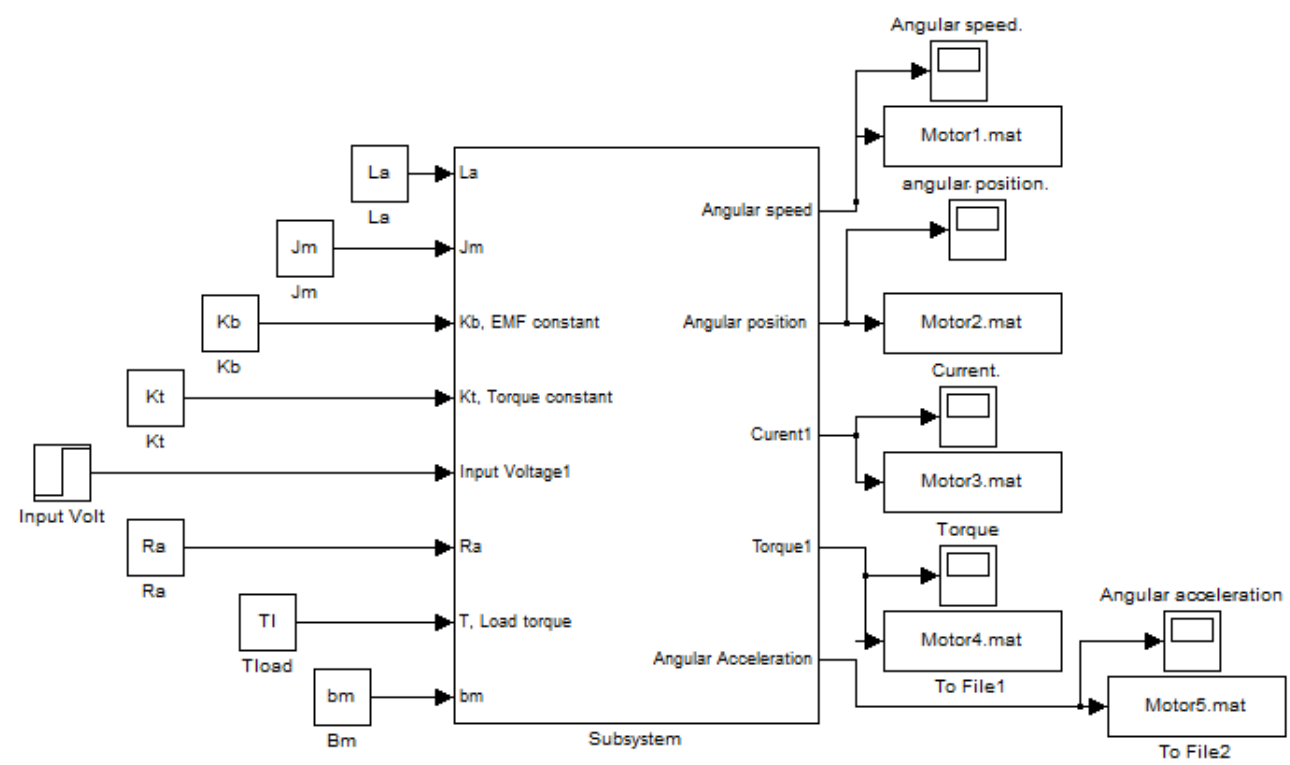

Fig. 8(d): Accurate function block with its parameters window for open loop DC motor performance verification and analysis 


\subsection{Modeling and Analysis Using MATLAB.}

The transfer function can be defined and entered in MATLAB in a number of different ways ; by defining the variables in the transfer function, that are: $V_{i n}, R_{a}$, $l_{a}, K_{t}, K_{b}, J_{m}, b_{m}$ in polynomial coefficient form, then defining numerator and denominator, or we can separately enter transfer functions describing mechanical and electric DC motor characteristics ,then combine them in series, and finally using MATLAB function feedback to create a feedback connection of two transfer functions, a program m.file can be written to simplify analysis process, the following m.file can be used to return the transfer function relations $\mathrm{G}_{\text {angle }}(\mathrm{s})$, $\mathrm{G}_{\text {speed }}(\mathrm{s}), \theta_{\mathrm{m}}(\mathrm{s}) / T_{m}(s), I_{a}(s) / V_{\text {in }}(s)$,simplified $\mathrm{G}_{\mathrm{speed}}(\mathrm{s})$, simplified $\mathrm{G}_{\mathrm{angle}}(\mathrm{s})$ as well as their response to step input signal, shown in Fig. 10

clc, close all, clearall

$\operatorname{Vin}=12 ; \mathrm{Jm}=0.02 ; b m=0.03 ; \mathrm{Kt}=0.023 ; \mathrm{Kb}=0.023$; $R a=1 ; L a=0.23 ; T L=0$;

$\% \mathrm{Jm}=$ input(' Enter moment of inertia of the rotor, $\left.(J m)=^{\prime}\right)$;

$\%$ bm $=$ input(' Enter damping constant of the mechanical system,$\left.(\mathrm{bm})={ }^{\prime}\right)$;

$\% K t=$ input(' Enter torque constant, $\left.K t={ }^{\prime}\right)$;

$\% \mathrm{~Kb}=$ input(' Enter electromotive force constant, $\left.K b=^{\prime}\right)$;

$\%$ Ra = input ('Enter electric resistance of the motor armature (ohms), $\left.R a=^{\prime}\right)$;

$\%$ La =input(' Enter electric inductance of the motor armature (Henry), La=');

$\%$ Vin = input(' Enter applied input voltage, Vin $=')$; numl $=[1]$;

$\operatorname{den} 1=[L a, R a]$

num2 = [1];

$\operatorname{den} 2=[\mathrm{Jm}, \mathrm{bm}]$

$A=\operatorname{conv}([\mathrm{La}, \mathrm{Ra}],[\mathrm{Jm}, \mathrm{bm}])$;

$T F 1=t f(K t, A)$;

disp('DC motor electric part Transfer

function, output current: ')

G_electric $=t f($ numl 1, den 1$)$

disp('DC motor mechanical part Transfer function o,output speed: ')

G_mechanical $=t f($ num 1, den 2$)$

disp('DC motor system open loop Transfer

function, output angle')

G_speed $=$ feedback $(T F 1, K b)$

disp('DC motor system open loop Transfer

function, output speed ')

$G \_$angle $=t f(1,[1,0]) * G \_$speed

disp('Transfer function relating torque developed by

the motor, $\operatorname{Tm}(s)$ and shaft angle? $\left.\mathrm{m}(\mathrm{s}),{ }^{\prime}\right)$

G_torque_angle $=t f(1,[\mathrm{Jm}, \mathrm{bm}, 0])$

disp('Transfer function relating torque developed by the motor, $\operatorname{Tm}(s)$ and shaft speed, ')

G_torque_speed $=t f(1,[\mathrm{Jm}, \mathrm{bm}])$
disp('Transfer function relating input Vin(s)and output current $I(s)$ : ')

$G_{-}$Current $=t f([1 / \mathrm{La}, 1 / \mathrm{Jm}]$,

$[1,((R a / L a)+(b m / J m)),((R a * b m) /(L a * J m))+((K b * K t) /(L$ $a * J m))]$ )

disp('Simplified Transfer function relating input

$\operatorname{Vin}($ s)and output angle: ')

$G \_a n g l e \_s i m p l=t f\left(K t,\left[R a^{*} J m,\left(R a * b m+K t^{*} K b\right), 0\right]\right)$

disp('Simplified Transfer function relating input

$\operatorname{Vin}(s)$ and output speed:')

$G \_s p e e d \_s i m p l=t f(K t,[R a * J m,(R a * b m+K t * K b)])$

subplot(4,2,1), step(Vin*G_angle),title('Step

response, outputangle')

subplot(4,2,2), step(Vin*G_speed),title('Step

response, output speed ')

subplot (4,2,3), step (Vin *G_torque_angle),title('Step

response, input motor torque output angle')

subplot $(4,2,4)$,step (Vin $* G_{-}$Current), title( 'Step

response, Vin output current')

subplot (4,2,5),step $\left(G \_a n g l e \_s i m p l\right), t i t l e($ 'Simplified

response, output angle ')

subplot $(4,2,6)$, step $\left(V i n * G \_s p e e d \_s i m p l\right)$,title( 'Simplif

ied response, output speed ')

$\%$ state space

$n u m=K t$;

den_speed $=$

$[(\mathrm{Jm} * \mathrm{La}),(\mathrm{Jm} * \mathrm{Ra})+(\mathrm{La} * b m),(R a * b m)+(K t * K b)]$;

den_angle $=$

$[(J m * L a),(J m * R a)+(L a * b m),(R a * b m)+(K t * K b), 0]$;

$G_{\text {_speed }}=t f($ num,den_speed $)$;

$G \_$anle $2=t f(1,[1,0]) * G \_$speed 2 ;

disp ('State matrix, output angle: ')

$[A 1, B 1, C 1, D 1]=t f 2 s s($ num, den_angle $)$

subplot(4,2,7), step $(A 1, B 1, C 1, D 1)$, title('state

space response, output angle')

disp('State matrix, output speed: ')

$[A, B, C, D]=t f 2 s s($ num, den_speed $)$

subplot $(4,2,8), \operatorname{step}(\operatorname{Vin} * A, \operatorname{Vin} * B, \operatorname{Vin} * C, \operatorname{Vin} * D)$,

title('state space response, output speed ')

$\%$ steady state calculations:\% for velocity steady state value

$t=0: 0.01: 1000$;

$y=\operatorname{step}\left(12 * G_{-}\right.$speed,t $)$;

speed_steady_state_value $=y($ length $(t))$;

fprintf(' Output steady state speed, OMEGA=\%f

$\mathrm{rad} / \mathrm{sec} \backslash n$ ',speed_steady_state_value)

$\%$ for angle steady state value

$y=\operatorname{step}\left(12 * G \_\right.$angle,t $)$;

angle_steady_state_value $=y($ length $(t))$;

fprintf('Output steady state angle for given time range, THETA $=\%$ radians $\backslash n$

',angle_steady_state_value)

\section{Modeling of Separately Excited DC Motor}

7.1 Modeling of the field current controlled DC motor, with $i_{a}(t)$ held constant 
A simplified equivalent representation of the field controlled DC motor's two components are shown in Fig.2(b). it consists of independent two circuits, armature circuit and field circuit, in which loads are connected to the armature circuit The voltage is applied to both to field and armature terminals, as shown , there are two currents, filed current, $\mathrm{i}_{\mathrm{f}}(\mathrm{t})$ and armature current, $\mathrm{i}_{\mathrm{a}}(\mathrm{t})$ in order to have linear system, one of these two currents most held constant. In the field current controlled DC motor, the armature current must maintained constant $\mathrm{i}_{\mathrm{a}}(t)=i_{a}=$ constant , and the field current, $\mathrm{i}_{\mathrm{f}}$ varies with time, $\mathrm{t}$, this yields:

The air-gap flux, $\Phi$ is proportional to the field current and given by:

$$
\varphi=K_{f}^{*} i_{f}
$$

The back EMF voltage is given by:

$$
\mathrm{EMF}=\mathrm{K}^{*} \Phi * \omega_{m}=V_{i n}-\mathrm{I}_{a} R_{a}
$$

The torque developed by the motor is related linearly to air-gap flux, $\Phi$ and the armature current $i_{a}(t)$, and given by:

$$
\text { Motor Torque }=T_{m}=K_{1} * \varphi * i_{a}(t)
$$

Substituting (30) in (31), we have:

$$
T_{m}=K_{1} * K_{f} * i_{a}(t) * i_{f}(t)
$$

The armature current must maintained constant $\mathrm{i}_{\mathrm{a}}(\mathrm{t})$ $=\mathrm{i}_{\mathrm{a}}=$ constant, yields:

$$
T_{m}=\left(K_{1} * K_{f} * i_{a}\right) * i_{f}(t)=K_{m} * i_{f}(t)
$$

Where $\mathrm{K}_{\mathrm{m}}$ : the motor constant. Based on the Newton's law combined with the Kirchoff's law, we obtain the mathematical model. Applying Kirchoff's law, Ohm's law, and Laplace transform to the stator field yields mathematical model describing the electrical characteristics of field controlled DC motor and given by:

$$
\sum V=V_{\text {in_field }}-V_{R_{-} \text {field }}-V_{L_{-} \text {field }}=0
$$

Applying Ohm's law, substituting and rearranging, we get differential equation that describes the electrical characteristics, given by:

$$
V_{\text {in_field }}=R_{f} i_{f}+L_{f}\left(\frac{d i_{f}(t)}{d t}\right)
$$

Taking Laplace transform and rearranging, gives:

$$
V_{\text {in_field }}(s)=\left(L_{f} s+R_{f}\right) I_{f}(s)
$$

$$
I_{f}(s)=\frac{\mathrm{V}_{\text {in_field }}(\mathrm{s})}{\left(\mathrm{L}_{\mathrm{f}} \mathrm{s}+\mathrm{R}_{\mathrm{f}}\right)}
$$

Where: $\mathrm{L}_{\mathrm{f}}$, statorinductance, $\mathrm{R}_{\mathrm{f}}$, stator resistance

The Mechanical characteristics of filed controlled DC motor; performing the energy balance on the DC motor system; the sum of the torques must equal zero, we have:

$$
\begin{gathered}
\sum T=J * \alpha=J^{*} d^{2} \theta / d t^{2} \\
T_{m}-T_{\alpha}-T_{\omega}=0
\end{gathered}
$$

The motor torque is related to the load torque, by:

$$
T_{m}-T_{\omega}=J * d^{2} \theta / d t^{2}
$$

$$
K_{m} * i_{f}(t)-b_{\mathrm{m}} * \mathrm{~s} \theta(\mathrm{s})=\mathrm{J}_{\mathrm{m}} * \mathrm{~s}^{2} \theta(\mathrm{s})
$$

Substituting (32) and rearranging, gives:

$$
K_{m} * \frac{\mathrm{V}_{\text {in_field }}(\mathrm{s})}{\left(\mathrm{L}_{\mathrm{f}} \mathrm{s}+\mathrm{R}_{\mathrm{f}}\right)}-b_{m} s \theta(\mathrm{s})=\mathrm{J}_{\mathrm{m}} \mathrm{s}^{2} \theta(\mathrm{s})
$$

Rearranging Eq.(33), the electrical and mechanical field current controlled DC motor components are coupled to each other through an algebraic the motor constant, $\mathrm{K}_{\mathrm{m}}$, we obtain the transfer function relating input filed voltage $V_{\text {in_field }}(s)$, and motor output angle $\theta_{m}(s)$, and given by:

$$
G_{\text {angle }}(s)=\frac{\theta(s)}{V_{\text {in_filed }}(s)}=\frac{K_{m}}{s\left[\left(L_{f} s+R_{f}\right)(J s+b)\right]}
$$

The simulink model of the filed current controlled DC motor is shown in Fig. (11), here note that the armature controlled DC motor is in nature closed loop system, while filed current controlled DC motor is open loop.

\subsection{Modeling of separately excited DC motor, with varying both $i_{a}(t)$ and $i_{f}(t)$}

Performing the energy balance on the DC motor system (Fig.2(b)); the sum of the torques must equal zero, we have:

$$
\begin{aligned}
& \sum T=J * \alpha=J^{*} d^{2} \theta / d t^{2} \\
& T_{e}-T_{\alpha}-T_{\omega}-T_{E M F}=0
\end{aligned}
$$

Setting, $\mathrm{Te}=K_{t} * i_{s} * i_{f}$, substituting, gives:

$$
K_{t} * i_{s} * i_{f}-T_{\text {Load }}-J_{m}\left(\frac{d^{2} \theta}{d t^{2}}\right)-b_{m}\left(\frac{d \theta}{d t}\right)=0
$$



for Mechatronics Applications, Using Different Approaches and Verification by MATLAB/Simulink

Taking Laplace transform and rearranging, gives:

$$
\begin{aligned}
& K_{t} * I_{a}(s) * I_{f}(s)-T_{\text {load }}-J_{m} * s^{2} \theta(s)-b_{m} *_{s} \theta(s)=0 \\
& K_{t} * I_{a}(s) * I_{f}(s)-T_{\text {load }}=\left(J_{m} s+b_{m}\right) s \theta(s) \\
& \frac{\omega(s)}{\left[K_{t} * I_{a}(s) * I_{f}(s)-T_{L}(s)\right]}=\left[\frac{1}{\left(J_{m} s+b_{m}\right)}\right] \\
& \omega(s)=\frac{\left[K_{t} * I_{a}(s) * I_{f}(s)-T_{L}(s)\right]}{\left(J_{m} s+b_{m}\right)}
\end{aligned}
$$

Applying Kirchoff's law around the field electrical loop by summing voltages throughout the R-L circu it gives:

$$
V_{f}=R_{f} * i_{f}(t)+L_{f}\left(\frac{d i_{f}(t)}{d t}\right)
$$

Taking Laplace transforms, rearranging to separate the field current, $\mathrm{i}_{\mathrm{f}}$ gives:

$$
\begin{gathered}
V_{f}=R_{f} * I_{f}(t)+L_{f} s I_{a} \\
I_{f}(s)=\frac{V_{f}}{\left(R_{f}+L_{f} s\right)}
\end{gathered}
$$

Applying Kirchoff's law around the armature electrical loop by summing voltages throughout the R-L circuit, taking Laplace transform, gives:

$$
\sum V=V_{i n}-V_{R}-V_{L}-E M F=0
$$

Setting, $\mathrm{EMF}=K_{b} * i_{f} * d \theta(t) / d t$, gives:

$$
\begin{gathered}
V_{a}=R_{a} * i_{a}(t)+L_{a}\left(\frac{d i_{a}(t)}{d t}\right)+K_{b} * i_{f} * \frac{d \theta(t)}{d t} \\
V_{i n}(s)=R_{a} I(s)+L_{a} s I(s)+K_{b} * i_{f} * s \theta(s)
\end{gathered}
$$

Rearranging to separate the armature current, $i_{a}$ gives:

$$
I_{a}(s)=\left[\frac{1}{\left(L_{a} s+R_{a}\right)}\right]\left[V_{a}(s)-K_{b} * i_{f} * \omega(s)\right]
$$

Substituting in (34) .(35), gives:

$$
\begin{aligned}
& K_{t} * i_{f} *\left[\frac{1}{\left(L_{a} s+R_{a}\right)}\right]\left[V_{i n}(s)-K_{b} * i_{f} * \omega(s)\right]-T_{\text {load }} \\
& =J_{m} s^{2} \theta(s)+b_{m} s \theta(s)
\end{aligned}
$$

Rearranging, the transfer function relating input armature voltage to output motor angular speed given by:

$$
\begin{aligned}
& \frac{\omega(s)}{V_{\text {armature }}(s)} \\
& =\frac{\frac{K_{t} I_{f}}{R_{a} R_{f} b}}{\left(\frac{L_{a} J}{R_{a} b}\right) s^{2}+\left(\frac{L_{a}}{R_{a}}+\frac{J}{b}\right) s+\left(1+\frac{\left(K_{b} V_{\text {field }}\right)}{R_{a} R_{f}^{2} b}\right)}
\end{aligned}
$$

Using these equation, the simulink model shown in Fig.12(a), of separately excited DC motor, can be built. Another modified from simulink model from [16] is shown in Fig.12(b), in this model the couple resisting, mutual inductance and coefficient of friction are introduced.
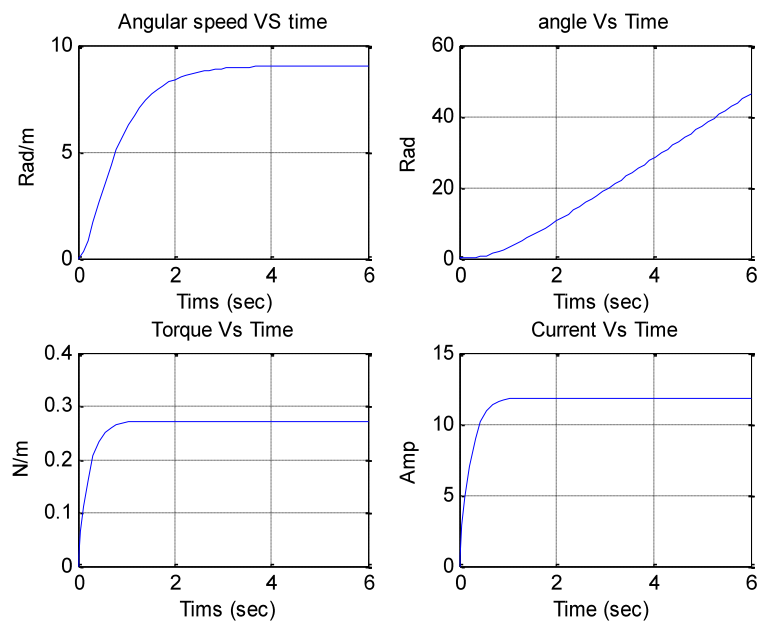

Fig. 9(a): T orque/time, Speed/time, Position/time and Current/time curves for $12 \mathrm{~V}$ step input
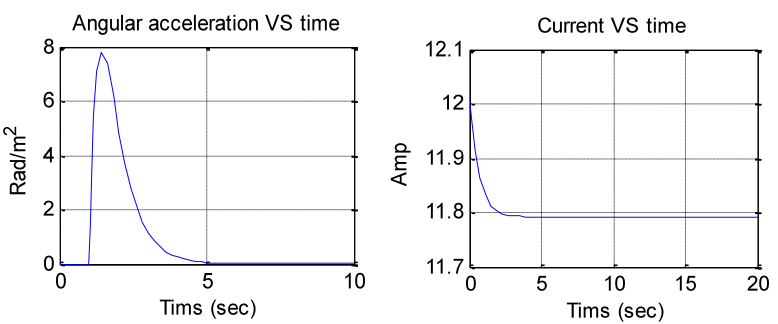

Fig. 9(b): Angular acceleration/time curve, and simplified model current/time curve , both for $12 \mathrm{~V}$ step input 

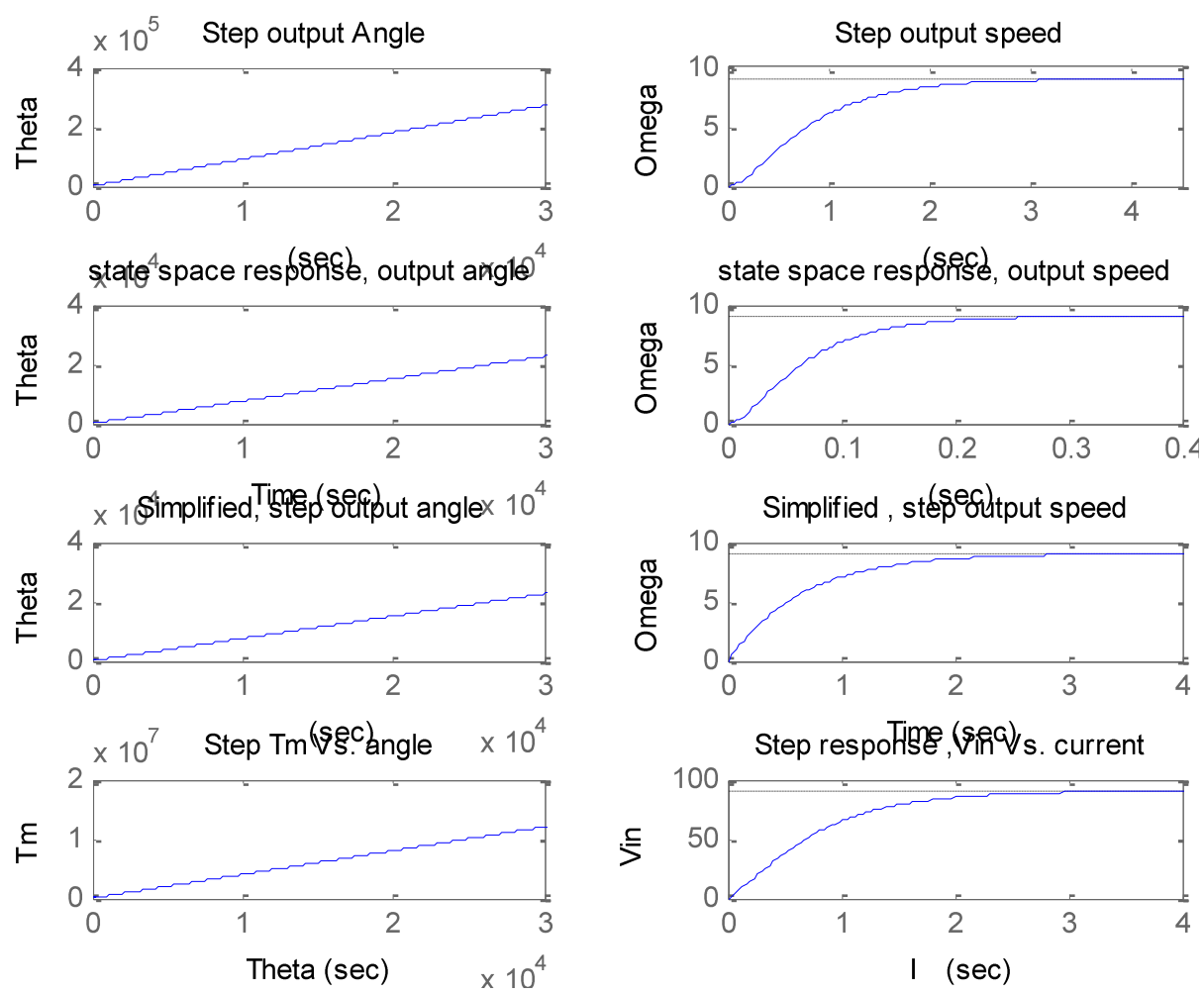

Fig. 10: Response curves obtained by running suggested $m$.file

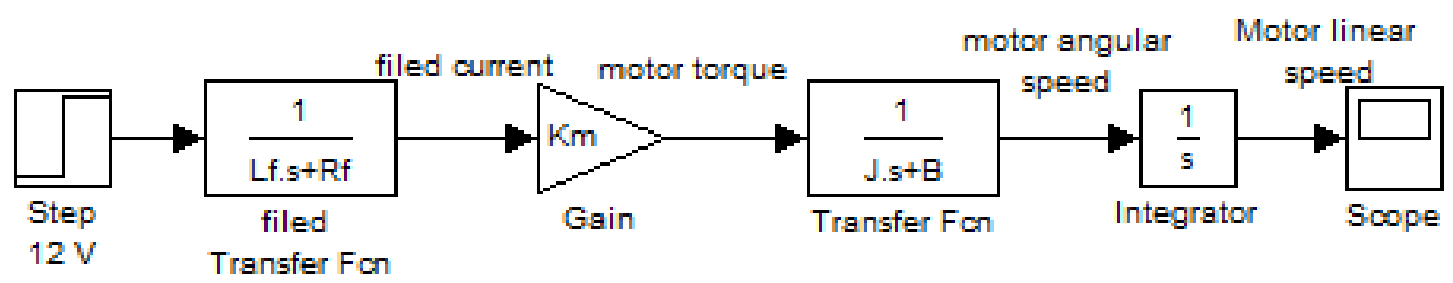

Fig. 11: Simulink model of the filed current controlled DC motor

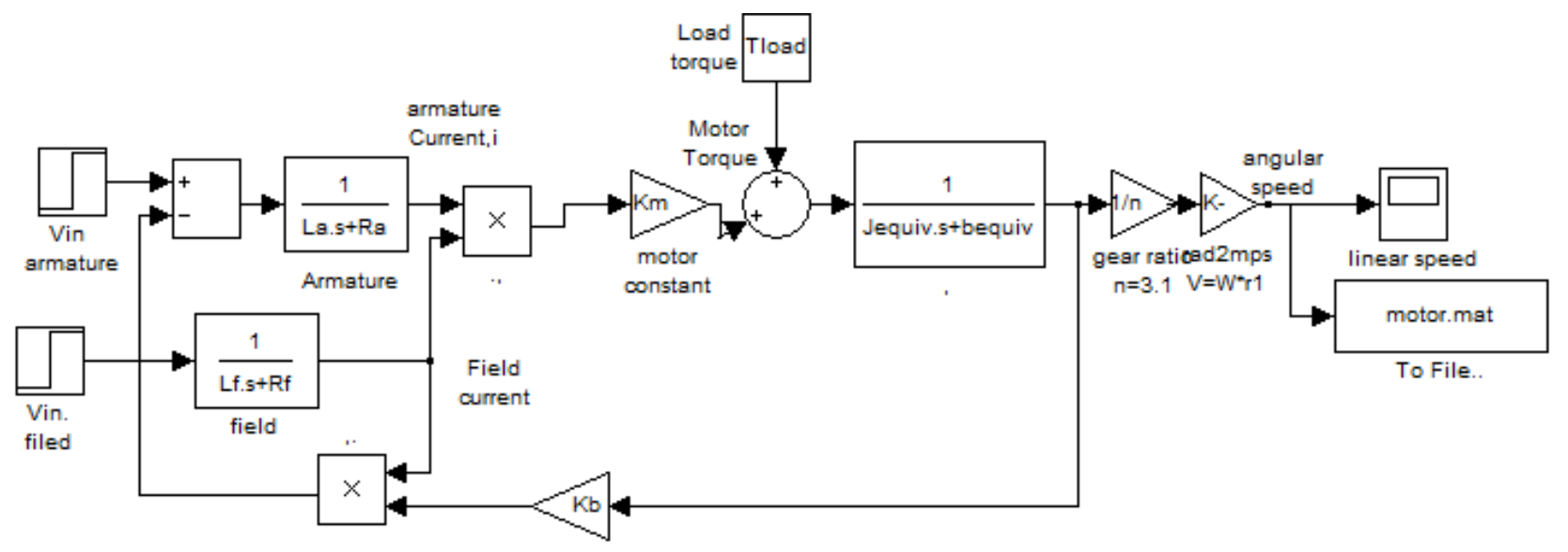

Fig. 12(a) 


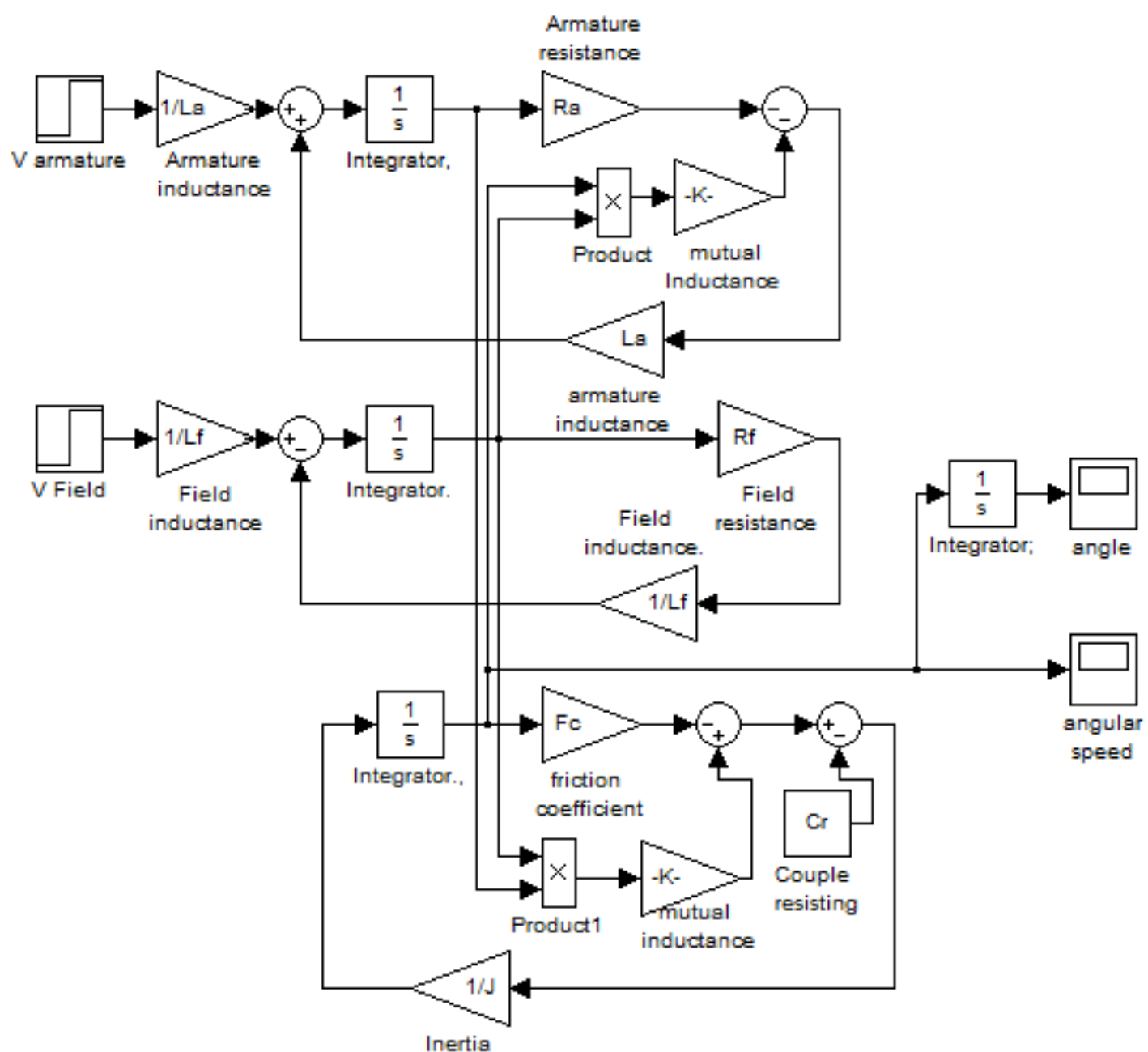

Fig. 12(b)

Fig. 12(a)(b): Simulink model of separately excited DC motor

\section{Conclusion}

To simplify and accelerate the process of selection, modeling, simulation and dynamic analysis of electric DC motors for specific mechatronics applications, this paper presents modeling, simulation and analysis of the basic open loop DC motor system, using different approaches and verification using MATLAB/simulink software, for different application, different mathematical and simulink models, as well as, a MATLAB m.file and function block models are derived, built and introduced, these models intended for research purposes as well as for the application in educational process, obtained response curves in terms of output torque/time, angular speed/time, angular position/time, angular acceleration/time and current/ time for $12 \mathrm{~V}$ step input for used DC motor, reflect the accuracy and applicability of derived models for research purposes in selection, performance analysis and control of electric motors, as well as for research purposes and application in educational process.

\section{References}

[1] M. S. RUSU, and L. Grama, The Design of a DC Motor Speed Controller, Fascicle of Management and Tech. Eng., Vol. VII (XVII), 2008, pp. 1055 1060 .

[2] Chun Htoo Aung, Khin Thandar Lwin, and Yin Mon Myint, Modeling Motion Control System for Motorized Robot Arm using MATLAB, World Academy of Science, Engineering and Technology 422008.

[3] Halila A., Étude des machines à courant continu, MS Thesis, University of LAVAL, (Text in French), May 2001.

[4] Capolino G. A., Cirrincione G., Cirrincione M., Henao H., Grisel R., Digital signal processing for electrical machines, International Conference on Electrical Machines and Power Electronics, Kusadasi(Turkey), pp.211-219, 2001.

[5] M.P.Kazmierkowski, H.Tunia "Automatic Control of Converter-Fed Drives", Warszawa 1994. 
[6] R.D. Doncker, D.W.J. Pulle, and A. Veltman. Advanced Electri-cal Drives: Analysis, Modeling, Control. Springer, 2011.

[7] Grzegorz SIEKLUCKI,Analysis of the TransferFunction Models of Electric Drives with Controlled Voltage Source PRZEGL , AD ELEKTROTECHNICZNY (Electrical Review), ISSN 0033-2097, R.88NR7a/2012.

[8] Richard C. Dorf and Robert H. Bishop. Modem Control Systems. Ninth Edition, Prentice-Hall Inc., New Jersey, 2001.

[9] Norman S. Nise, Control system engineering, sixth edition, John Wiley \& Sons, Inc, 2011.

[10] P. Wolm, X.Q. Chen, J.G. Chase, W. Pettigrew, C.E. Hann1, Analysis of a PM DC Motor Model for Application in Feedback Design for Electric Powered Mobility Vehicles.

[11] Slotine E, Li W. Applied nonlinear control. USA: Prentice Hall Inc.; 1991.
[12] Faber MN, Estimating the uncertainty in estimates of root mean square error of prediction: Application to determining the size of an adequate test set in multivariate calibration. Chemometr Intel Lab 1999;49(1):79-89.

[13] The MathWorks (www.mathworks.com), Control System Toolbox documentation Version V5.2 (R2009b).

[14] Katsuhiko Ogata, Modern control engineering, third edition, Prentice Hall, 1997.

[15] Boumediene Allaua, Abdellah Laoufi, Brahim GASBAOUI, Abdelfatah NASRI and Abdessalam Abdelrahmani Intelligent Controller Design for DC Motor Speed Control based on Fuzzy LogicGeneticAlgorith ms Optimization.http://ljs .acade mic direct. org/ A13/090_102.htm

\section{Appendix I: Table-Nomenclature}

\begin{tabular}{|c|c|c|}
\hline Symbol & Quantity & UNIT \\
\hline V, or Vin & The applied input voltage,(Motor terminal voltage) & Volte, V \\
\hline$V_{\text {in_field }}(s)$ & Input filed voltage & Volte, V \\
\hline$R_{a}$ & Armature resistance,( terminal resistance) & $\mathrm{Ohm}, \Omega$ \\
\hline $\mathrm{R}_{\mathrm{f}}$ & Stator resistance & $\mathrm{Ohm}, \Omega$ \\
\hline $\mathrm{L}_{\mathrm{f}}$ & Stator inductance & \\
\hline $\mathrm{L}_{\mathrm{a}}$ & Armature inductance & \\
\hline$\Phi$ & Air-gap flux, & \\
\hline$i_{a}$ & Armature current & Ampere, A \\
\hline$I_{f}$ & Field current & \\
\hline$K_{t}$ & Motor torque constant & N.m/A \\
\hline$K_{e}$ & Motor back-electromotive force const. & $\mathrm{V} /(\mathrm{rad} / \mathrm{s})$ \\
\hline $\mathrm{K}_{\mathrm{m}}$ & The motor constant & \\
\hline$\omega_{m}$ & Motor shaft angular velocity & $\mathrm{rad} / \mathrm{s}$ \\
\hline$T_{m}$ & Torque produced by the motor & N.m \\
\hline$J_{m}$ & Motor armature moment of inertia & $\mathrm{kg} \cdot \mathrm{m}^{2}$ \\
\hline$J_{\text {total }}$ & Total inertia $=\mathrm{Jm}+\mathrm{Jload}$ & kg.m $\mathrm{m}^{2}$ \\
\hline$L_{a}$ & Armature inductance & Henry, $\mathrm{H}$ \\
\hline$b$ & Viscous damping, friction coefficient & N.m/rad.s \\
\hline $\mathrm{e}_{\mathrm{a}}, E M F$ : & The back electromotive force, $E M F=K_{b} d \theta / d t$ & $\mathrm{e}_{\mathrm{a}}, E M F$ \\
\hline$\theta_{\mathrm{m}}$ & Motor shaft output angular position & radians \\
\hline$\omega_{\mathrm{m}}$ & Motor shaft output angular speed & $\mathrm{rad} / \mathrm{sec}$ \\
\hline$V_{R}=R * i$ & The voltage across the resistor & Voltage \\
\hline $\boldsymbol{V}_{\boldsymbol{L}}=L d i / d t$ & The voltage across the inductor & Voltage \\
\hline$T_{\text {load }}$ & Torque of the mechanical load & $T_{\text {load }}$ \\
\hline $\mathrm{T} \alpha$ & Torque du to rotational acceleration & $\mathrm{T} \alpha$ \\
\hline$T \omega$ & Torque du to rot ational velocity & $T \omega$ \\
\hline $\mathrm{T}_{\mathrm{EMF}}$ & The electromagnetic torque. & TEMF \\
\hline
\end{tabular}




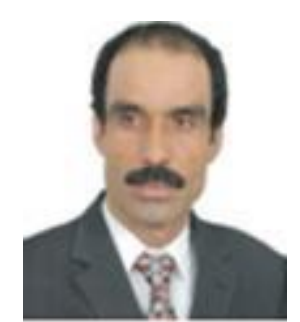

Ahmad A. Mahfouz: B.Sc. and M.Sc; Bari University, Italy and Moscow state Academy. Now, He in Automatic and Mechatronics Systems, Vladimir State University and the director of alpha center for engineering studies and technology researches. Major academic and research interests: Design, modeling and analysis of primary Mechatronics Machines Control Systems, Robotics, Electronics, Microcontrollers, and Quantity Surveying.

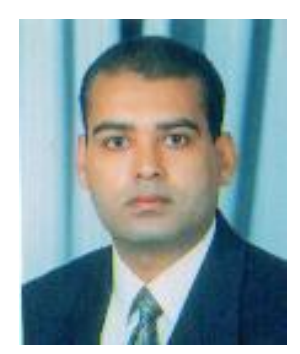

Mohammed M. K. Was born in Kena, Egypt, in 1968. He received the B.Sc. and M.SC. degrees in Production Engineering and Design dept. from El-Minia university Egypt, 92 and 96 respectively. He received the $\mathrm{Ph} . \mathrm{D}$ degree in Mechanical Engineering Hannover university Germany, 2004. since $2010 \mathrm{He}$ is working as an Associate Professor in the Department of, Production Engineering and Design dept. El-Minia,. He is currently an Associate Professor in the Department of Mechanical Engineering, Faculty of Engineering, Taif University, Saudi Arabia, his publications about forty research in the fields of non-conventional machining (ECM ,WJ and $\mathrm{AWJ}$ ) and Tribology.

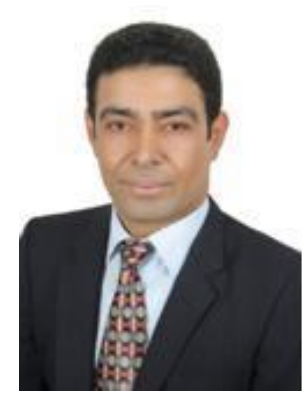

Farhan Atallah Salem: B.Sc., M.Sc and Ph.D., in Mechatronics of production systems, Moscow state Academy. Now he is ass. Professor in Taif University, Mechatronics program, Dept. of Mechanical Engineering and gen-director of alpha center for engineering studies and technology researches. Research Interests; Design, modeling and analysis of primary Mechatronics Machines, Control selection, design and analysis for Mechatronics systems. Rotor Dynamics and Design for Mechatronics applications

How to cite this paper: Ahmad A. Mahfouz, Mohammed M. K., Farhan A. Salem,"Modeling, Simulation and Dynamics Analysis Issues of Electric Motor, for Mechatronics Applications, Using Different Approaches and Verification by MATLAB/Simulink", International Journal of Intelligent Systems and Applications(IJISA), vol.5, no.5, pp.39-57, 2013.DOI: 10.5815/ijisa.2013.05.06 